\title{
Targeting Autophagy as a Strategy for Developing New Vaccines and Host-Directed Therapeutics Against Mycobacteria
}

\author{
Emily J. Strong and Sunhee Lee* \\ Department of Microbiology and Immunology, University of Texas Medical Branch, Galveston, TX, United States
}

Mycobacterial disease is an immense burden worldwide. This disease group includes tuberculosis, leprosy (Hansen's disease), Buruli Ulcer, and non-tuberculous mycobacterial (NTM) disease. The burden of NTM disease, both pulmonary and ulcerative, is drastically escalating globally, especially in developed countries such as America and Australia. Mycobacteria's ability to inhibit or evade the host immune system has contributed significantly to its continued prevalence. Pre-clinical studies have highlighted promising candidates that enhance endogenous pathways and/or limit destructive host responses. Autophagy is a cell-autonomous host defense

OPEN ACCESS

Edited by:

Chinnaswamy Jagannath, Weill Cornell Medical College of Cornell University, United States

Reviewed by: Roberta Olmo Pinheiro, Oswaldo Cruz Foundation, Brazil Rosane M. B. Teles, University of California, Los Angeles, United States

*Correspondence: Sunhee Lee sunhlee@utmb.edu

Specialty section:

This article was submitted to Microbial Immunology, a section of the journal

Frontiers in Microbiology

Received: 05 October 2020 Accepted: 21 December 2020

Published: 14 January 2021

Citation:

Strong EJ and Lee S (2021) Targeting Autophagy as a Strategy for Developing New Vaccines and Host-Directed Therapeutics

Against Mycobacteria.

Front. Microbiol. 11:614313. doi: 10.3389/fmicb.2020.614313 mechanism by which intracytoplasmic cargos can be delivered and then destroyed in lysosomes. Previous studies have reported that autophagy-activating agents, small molecules, and autophagy-activating vaccines may be beneficial in restricting intracellular mycobacterial infection, even with multidrug-resistant strains. This review will examine how mycobacteria evade autophagy and discusses how autophagy could be exploited to design novel TB treatment strategies, such as host-directed therapeutics and vaccines, against Mycobacterium tuberculosis and NTMs.

Keywords: autophagy, mycobacteria, host-directed therapies, non-tuberculous mycobacteria, host-microbe interactions, vaccines

\section{INTRODUCTION}

While TB is a disease of significant global burden, the burden of non-tuberculosis mycobacteria (NTM) disease is higher than TB in many developed countries such as the United States and Australia (Prevots et al., 2010). NTMs are mycobacteria other than Mycobacterium tuberculosis $(M t b)$ and Mycobacterium leprae (the cause of leprosy/Hansen's Disease). Globally, the burden of NTM continues to increase substantially. Like many pathogenic diseases, drug-resistance has become a severe public health concern for mycobacterial infection. In 2018, there were approximately 500,000 new rifampicin-resistant TB cases, most of which also comprised multiple drug-resistant infections (World Health Organisation, 2020). In contrast, the NTM species display significant heterogeneity in their susceptibility to standard anti-TB drugs and thus the treatment for NTM diseases usually involves the use of macrolides and injectable aminoglycosides. Although well-established international guidelines are available, treatment of NTM disease is mostly empirical and not entirely successful. In general, the treatment duration is much longer for NTM diseases, compared to TB. Taken together, the considerable global burden of mycobacterial disease requires much needed further research and the development of new treatment and prevention strategies. 
The development of $\mathrm{TB}$ disease occurs in only $10 \%$ of individuals exposed to the pathogen, which infers that competent host defense mechanisms exist to control the infection. In the last decade, autophagy has surfaced as an essential host immune defense mechanism against intracellular $M t b$ infection. Autophagy is a complex, essential, conserved cellular process allowing for the degradation of intracellular components, including proteins, organelles, and foreign bodies. Autophagy targeting by host-directed therapies to enhance treatment options against pathogenic viruses and bacteria has recently become a popular research topic. Similarly, autophagy has been proven not only as an effective antimicrobial mechanism for the clearance of $M t b$ and NTMs, but as a process preventing excessive inflammation to avoid adverse effects of infection on the host. Still, increasing evidence shows that in order to augment its intracellular survival, mycobacteria has evolved multiple strategies to prevent the optimal operation of host autophagic machinery.

This review will focus on autophagy during mycobacterial infection. However, it is worth noting that many intracellular pathogens are known to modulate autophagy to promote their survival. For example, Legionella pneumophila secrets bacterial effector that irreversibly inactivates Atg8 proteins unable to be reconjugated by the Atg7-Atg3 (Choy et al., 2012). Many other intracellular bacteria like Shigella, Salmonella, and Mycobacteria also secrete bacterial effectors that inhibit autophagy (Ogawa et al., 2005; D'Cruze et al., 2011; Popa et al., 2016; Saini et al., 2016; Jiao and Sun, 2019; Strong et al., 2020). A deeper understanding of the mechanisms by which these bacteria cause disease should foster better treatment options. Ongoing analysis is even more critical, given the rising infection rates of NTMs and rapidly growing mycobacteria (RGM), increased prevalence of drugresistant $\mathrm{TB}$, and $\mathrm{TB} /$ Diabetes and $\mathrm{TB} / \mathrm{HIV}$ comorbidity. This review will cover the current understanding of the molecular mechanisms by which mycobacteria can modulate autophagy. Additionally, it will discuss the potential for these insights to be utilized and harnessed to develop host-directed therapies as treatment options against mycobacterial diseases.

\section{AUTOPHAGY PATHWAY AS A GENERAL ANTIMICROBIAL DEFENSE}

Macroautophagy is the most widely studied form of autophagy and is an evolutionarily conserved pathway controlling quality and quantity of eukaryotic organelles and the cytoplasmic biomass (Svenning and Johansen, 2013). Macroautophagy involves the formation of a double membrane phagosome, which fuses with a lysosome (Parzych and Klionsky, 2013). It is a constitutive cellular process that is induced under stress conditions such as nutrient starvation, which degrades cytoplasmic material into metabolites and degrades cytoplasmic foreign bodies (Svenning and Johansen, 2013). Macroautophagy can be selective, as it recognizes specific marked components by various receptor proteins such as p62 (SQSTM1) (Svenning and Johansen, 2013). The degradation of pathogens is called Xenophagy, whereby bacteria are engulfed by autophagosomes and degraded after fusion with lysosomes to form autolysosomes. This review will focus on Xenophagy, which will hereafter be referred to as "autophagy." The autophagy pathway is illustrated in Figure 1A, showing the minimal core components relevant for the discussion in this review.

The formation of the autophagosome and the fusion to a lysosome is broken down into five main steps (Figure 1A): (i) initiation, (ii) elongation, (iii) maturation, (iv) fusion, and (v) degradation. Autophagy initiation is regulated by the master regulator, the mammalian/mechanistic target of Rapamycin (mTOR). It is a negative regulator of autophagy, meaning its dephosphorylation is responsible for autophagy induction. Dephosphorylation of mTOR results in the translocation of the Unc-51 like autophagy activating kinase (Ulk1/2)Autophagy related (Atg)13-FAK family-interacting protein (FIP200)-Atg101 complex to the endoplasmic reticulum (Itakura and Mizushima, 2010; Mizushima, 2010). The Class III phosphatidylinositol 3 kinase (PI3K) activates the VPS34Beclin1-VPS15-Atg14 complex. The PI3K complex induces phosphatidylinositol-3-phosphate [PtdIns(3)P], which then recruits double FYVE-containing protein 1 (DFCP1) and WD-repeat domain phosphoinositide-interacting (WIPI) family proteins to initiate the omegasome formation (Axe et al., 2008; Matsunaga et al., 2009; Itakura and Mizushima, 2010; Polson et al., 2010). Elongation of the omegasome into the autophagosome is conducted by the Atg7-Atg10 complex and then conjugated to Atg12-Atg5-Atg16L on the omegasome membrane (Fujita et al., 2008). Atg4 cleaves LC3 into LC3-I, while the Atg7-Atg3 complex lipidates LC3-I into LC3-II by conjugating phosphatidyl-ethanolamine (PE). The completed autophagosome fuses with the lysosome to degrade the autophagosome cargo for subsequent metabolite recycling or antigen presentation (Knodler and Celli, 2011; Levine et al., 2011; Münz, 2016; Saini et al., 2016; Yu et al., 2018).

\section{AUTOPHAGY AND TUBERCULOSIS}

\section{Autophagy Induction by $M$. tuberculosis}

The global prevalence of mycobacterial diseases of all types has increased considerably. The most significant mycobacterial disease is tuberculosis (TB). In 2018, 1.4 million deaths were attributed to $M t b$ infection (World Health Organisation, 2020), meaning $\mathrm{TB}$ is one of the top 10 causes of death and the leading cause of worldwide death from a single infectious agent. One-quarter of the world's population is infected with Mtb. Approximately 5 to $10 \%$ of infections progress to the active disease at some point in their host lives. $M t b$ is a successful pathogen due to its capacity to evade the host immune systems and utilize phagocytes as a replication niche. The bacteria can significantly inhibit the phagolysosome's acidification and limit phagosome maturation, thereby forcing the infected cell to undergo programmed cell death (Russell et al., 2002). Several of the seminal observations regarding the antimicrobial role of autophagy have been made using Mtb (Gutierrez et al., 2004; Castillo et al., 2012) and such observations were followed by a gradual increase in studies on autophagy as a cell-autonomous, 


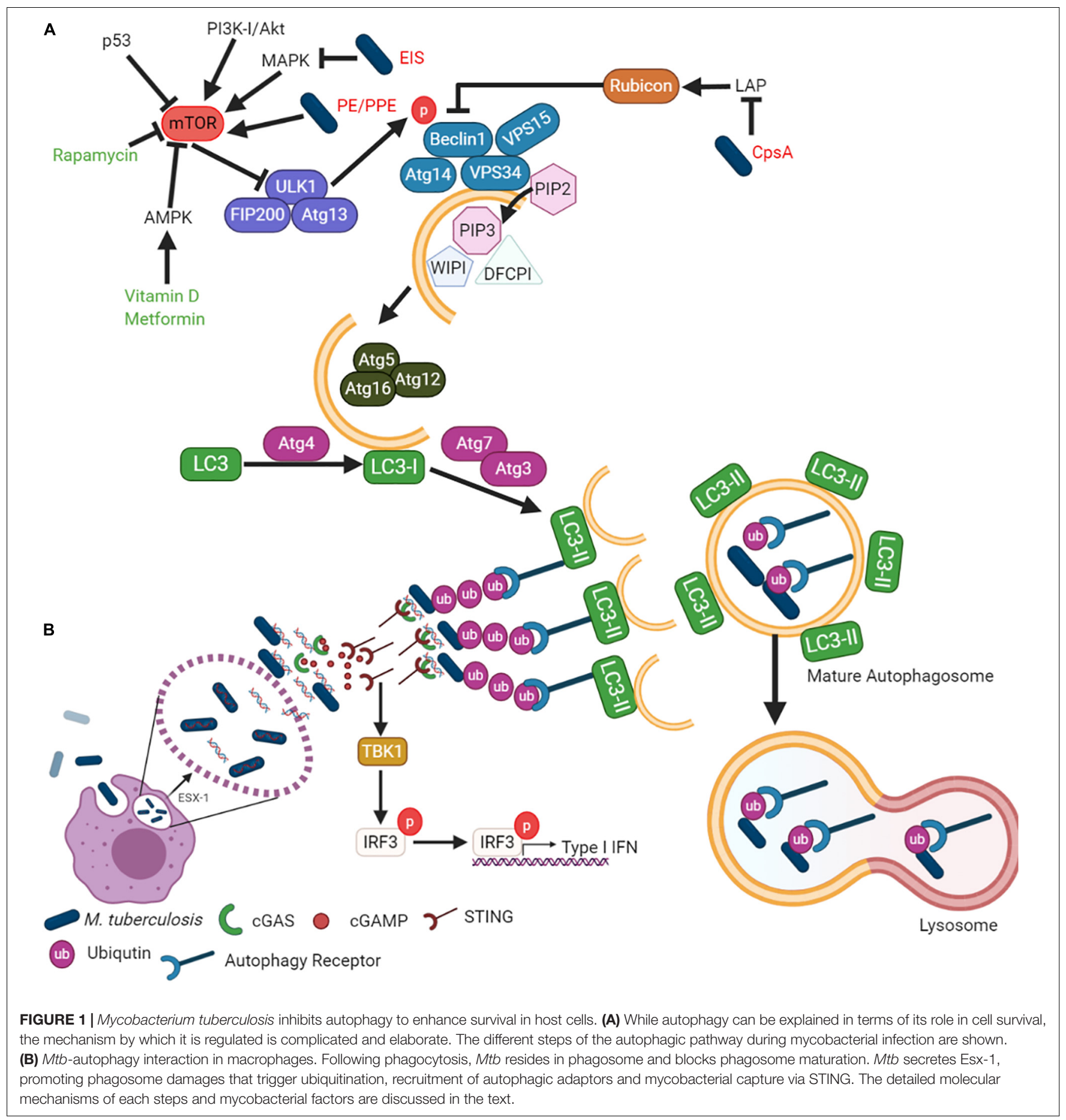

pharmacologically, physiologically and immunologically inducible anti-mycobacterial process (Gutierrez et al., 2004; Seto et al., 2012; Watson et al., 2012; Sakowski et al., 2015). These studies revealed the colocalization of $M t b$ with autophagosomes and increased bacterial clearance during autophagy induction (Gutierrez et al., 2004; Seto et al., 2012; Watson et al., 2012; Sakowski et al., 2015). Most of these models have been explored in the context of Atg5 and its effect on autophagy. Examination of other important autophagy markers such as Ulk1 and Atg4b in vivo has uncovered that Atg5 may play a role independent of canonical autophagy in Mtb control (Kimmey et al., 2015).

Infection with mycobacteria induces significant levels of proinflammatory cytokines, known to be inducers of autophagy. However, little colocalization of $M t b$ and autophagosomes has been observed without non-mycobacterial stimulation of autophagy. An example of immunological induction of 
mycobactericidal autophagy includes stimulation of infected macrophages with Th1 cytokines such as IFN- $\gamma$ and TNF$\alpha$ in a process that can be antagonized by Th2 cytokines including IL-4 and IL-13 (Harris et al., 2007; Ghadimi et al., 2010). Physiological induction of autophagy by IFN- $\gamma$ generated significant autophagosome formation in mycobacteria-infected macrophages and dendritic cells. Although $M t b$ infection causes a robust IFN- $\gamma$ response, the autophagy induction by virulent $M t b$ is limited, probably because mycobacteria inhibit IFN- $\gamma$ mediated autophagy induction (Zullo and Lee, 2012a; Zullo et al., 2014). IFN- $\gamma$ also plays a critical role in the nitric oxide (NO) response to $M t b$ infection. The deletion of IFN $-\gamma$ significantly impedes NO production and leads to uncontrolled replication of bacilli in vivo (Cooper et al., 1993; Flynn et al., 1993). The inhibition of NO has previously been shown to induce autophagy substrates' clearance, highlighting the complex role of cytokine signaling in autophagy pathways (Sarkar et al., 2011). Virulent Mtb infection induces TNF- $\alpha$, which is inactivated by the increased release of TNFR2 and results in inhibition of apoptosis (Balcewicz-Sablinska et al., 1998; Keane et al., 2000). This observation underscores the potential of virulent $M t b$ to inhibit autophagy by modulating cytokines' bioreactivity known to induce autophagy.

\section{Manipulation of Autophagy Pathways by Mycobacterial Factors}

Several bacterial effector proteins are known to modulate autophagy. Many of these effectors are secreted through the type I to type VII and type IX secretion systems (Jiao and Sun, 2019). Mycobacteria has numerous Type VII secretion systems (Esx1 - Esx5). Mtb ESX-1 is responsible for the puncture of the phagosome, allowing for mycobacterial escape (Conrad et al., 2017) (Figure 1B). Mtb cytosolic DNA is recognized by the cytosolic DNA sensor, cyclic GMP-AMP synthase (cGAS), resulting in the release of cyclic guanosine monophosphate (cGAMP). cGAMP is recognized by the stimulator of interferon genes (STING), leading to type I IFN release and the recruitment of autophagy receptors p62, NDP52, and optineurin (Watson et al., 2012, 2015). These receptors are recruited to the ubiquitinated pathogen, thereby allowing for specific targeting by the autophagosome. The receptors contain an LC3 interaction region (LIR) to bind the LC3 autophagy protein (Thurston et al., 2009; Zheng et al., 2009; Wild et al., 2011).

EspB is a part of the Esx1 secretory apparatus responsible for the secretion of early secretory antigenic target-6 (ESAT6). Treatment of macrophages with $\mathrm{EspB}$ protein demonstrates downregulation of the IFN $-\gamma$ receptor IFN- $\gamma \mathrm{R} 1$, resulting in the inhibition of STAT-1 activation even in the presence of IFN- $\gamma$ (Huang and Bao, 2016). EspB and ESAT-6 are not the only $M t b$ proteins linked to the inhibition of autophagy. The "enhanced intracellular survival" (eis) gene of $M t b$ can confer enhanced survival of Mycobacterium smegmatis in macrophages. However, it is not required for the persistence of $M t b$ in these cells (Wei et al., 2000; Shin et al., 2010). During Mtb infection, eis significantly inhibits the activation of JNK, which prevents the induction of non-canonical autophagy through Atg7. JNK activation also induced reactive oxygen species (ROS) generation and significantly increased type 2 macrophage cell death by $M t b$ eis deletion mutant (Shin et al., 2010). Eis was also found to substantially inhibit the production of TNF- $\alpha$, IL-4, and IL6 , while simultaneously stimulating INF- $\gamma$ and IL-10 secretion (Lella and Sharma, 2007; Samuel et al., 2007; Shin et al., 2010).

$M t b$ inhibits autophagy to protect against bacterial clearance and host cell death, which also impedes antigen presentation. The Mtb PE_PGRS47 protein inhibits autophagy and limits MHC class II antigen presentation (Saini et al., 2016). Several other $M t b$ PE/PPE proteins are also known to inhibit autophagy. For example, Mtb PE_PGRS41 (Deng et al., 2017), Mycobacterium marinum MMAR_0242 (Singh et al., 2016), and Mtb PE_PGRS29 (Chai et al., 2019) interact with autophagy machinery. Mtb also secrets a probable ligase (CpsA) to inhibit the non-canonical autophagy pathway designated as LC3-associated phagocytosis (LAP) and NADPH oxidase (Köster et al., 2017) (Figure 1A). In contrast to canonical autophagosomes, LAP does not result in double-membrane structures and instead promotes rapid phagosome maturation (Fazeli and Wehman, 2017). This cellular process limits the phagocytosed pathogen's ability to replicate by expediting phagosome maturation while regulating the IFN pathway and antigen presentation.

Additionally, studies have found that virulent $M t b$, but not avirulent $M t b$, can inhibit autophagy flux in macrophages and dendritic cells in an ESAT-6 and PhoP dependent manner (Chandra et al., 2015). Autophagy flux is an important cellular mechanism that degrades autophagosome cargo, which allows nutrient recycling or antigen presentation. Increased autophagic flux was found to improve bacterial clearance from macrophages and dendritic cells (Romagnoli et al., 2012; Chandra et al., 2015). The maturation of $M t b$-containing autophagosomes into autolysosomes was inhibited by blocking recruitment of the late endosome marker Rab7 (Chandra et al., 2015). Inhibition of Rab5 conversion to Rab7 in endosomes is a well-established method in which mycobacteria inhibit lysosomal fusion (Via et al., 1997; Rink et al., 2005).

$M t b$ inhibits canonical and non-canonical autophagy by several means and it is apparent that the role of infectioninduced autophagy is complicated. While overcoming autophagy inhibition by $M t b$ could lead to better treatment options, further consideration should be given to evidence suggesting that $M t b$ can inhibit autolysosome formation (Chandra et al., 2015). Additionally, there may be value in examining host-directed therapies targeting mTOR-independent autophagy pathways (Schiebler et al., 2015), since $M t b$ infection markedly activates mTOR. Exploring alternative autophagy-inducing pathways may lead to more efficacious drugs and may prove more useful in patients presenting with co-disease such as TB/Diabetes.

\section{AUTOPHAGY AND NON-TUBERCULOSIS MYCOBACTERIA}

\section{NTM Disease}

NTM is the broad term for diseases caused by over 170 mycobacteria. The most commonly isolated specie is the Mycobacterium avium Complex (MAC), accounting for $71.1 \%$ 
of Australian cases and $31.3 \%$ of NTM cases in South America. M. avium is the most common species isolated in Europe, Asia, South America, and North America. At the same time, M. intracellulare is prevalent in South Africa and Australia (Johnson and Odell, 2014; Griffith, 2019; Gopalaswamy et al., 2020). M. avium, MAC, and M. intracellulare most commonly present as a pulmonary disease similar to TB. In 2013, a nearly six-fold increase in NTM cases were reported in America compared to the 1980s (Donohue and Wymer, 2016), with similar trends in the United Kingdom, Denmark, and Germany (Ratnatunga et al., 2020). Some studies have attributed this rise of NTM infections to a vaccination policy change from a blanket BCG vaccination to a limited vaccination only for specific groups (SAGE Working Group of BCG Vaccines and WHO Secretariat, 2017; Kontturi et al., 2018).

Other common NTMs include Mycobacterium fortuitum, Mycobacterium kansasii, Mycobacterium abscessus, M. marinum, and Mycobacterium ulcerans. NTMs are opportunistic environmental pathogens that are typically found in soil and water. Although NTM disease presentation is most commonly pulmonary, observation of lymphatic, skin/soft tissue and disseminated disease have been reported (Griffith et al., 2007; Bodle et al., 2008; Tortoli, 2009). Many species of mycobacteria can also cause ulcerative disease. Four main presentations of the mycobacterial ulcerative disease have been designated: (i) cutaneous $M t b$ infection, (ii) leprosy (the second most common mycobacterial disease; caused by $M$. leprae or Mycobacterium lepromatosis), (iii) Buruli Ulcer, the third most common mycobacterial disease (caused by M. ulcerans), and (iv) opportunistic infections caused by other non-tuberculosis mycobacteria such as M. marinum. Franco-Paredes et al. (2018) eloquently summarized the disease presentation of cutaneous mycobacterial infections in their 2018 review.

Besides $M t b, M$. leprae and $M$. ulcerans account for the next highest mycobacterial disease burdens. Buruli Ulcer, caused by $M$. ulcerans, primarily occurs in the West and Central Africa, Asia, South America, the western Pacific, and Australasia (Simpson et al., 2019). Unlike the well-studied $M t b$ and $M$. leprae, the mode of transmission of M. ulcerans remains unknown (Röltgen and Pluschke, 2015). As with other mycobacteria, treatment of Buruli Ulcer is costly and takes a long time. Traditional antimycobacterial antibiotics are used for treatment, including rifampicin, streptomycin, clarithromycin, and moxifloxacin. However, wound interventions, such as lymphedema management and surgery, are commonly used to speed up healing (Yotsu et al., 2018; Converse et al., 2019; World Health Organisation, 2019). Though leprosy transmission remains on the decline with less than 200,000 cases in 2017 (World Health Organization, 2016), improved treatment options are a vital resource for continued disease decline (Fischer, 2017; Maymone et al., 2020; Scollard, 2020). Leprosy broadly presents two different clinical manifestations; paucibacillary tuberculoid, which is characterized by negative smears for acid-fast bacilli, and multibacillary lepromatous, which is characterized by positive smears for acid-fast bacilli (Nath, 2016).

Mycobacteria's unique cell wall and some species' ability to form biofilms, spread by aerosolization, slow growth, and intrinsic antibiotic resistance, also contribute to their ability to survive in unique and low nutrient environments (De Groote and Huitt, 2006). Their lipid-rich cell wall influences the bacteria's ability to modulate autophagy (Zullo and Lee, 2012a). The ability to form biofilms and survive in low nutrient environments indicates that these bacteria can form unique replication niches within the hosts' cells that traditional mycobacterial drugs cannot penetrate to be effective (Islam et al., 2012).

\section{NTM and Autophagy}

The induction of autophagy by mycobacteria is speciesdependent. Although all mycobacteria elicit strong mTOR activation, most non-pathogenic mycobacteria simultaneously induce significant autophagy, unlike their pathogenic relatives (Zullo and Lee, 2012a). M. smegmatis is often utilized as a model organism to study pathogenic mycobacteria due to its short culture time and BSL2 classification (Deng et al., 2017). While a low concentration of mTOR-inhibiting drugs like Rapamycin and Torin are able to inhibit mTOR activation and induce autophagy during mycobacterial infection (Zullo et al., 2014), clearance of $M$. smegmatis requires up to 10 times higher quantity of those drugs than needed to inhibit mTOR activation. Interestingly, this killing was observed to be independent of LC3B or Atg5, indicating a non-canonical autophagy pathway is involved in the clearance of $M$. smegmatis from macrophages (Zullo et al., 2014). This interesting observation suggests that targeting a noncanonical autophagy pathway for mycobacterial treatment may be useful. It has previously been shown that treatment of $M t b$ infected macrophages with potent autophagy inducers such as M. smegmatis can clear bacteria (Singh et al., 2017).

The role of autophagy during NTM has not been studied extensively. However, evidence exists that genetic variants in the autophagy-related genes, nucleotide-binding oligomerization domain-containing 2 (NOD2), E3 ubiquitin-protein ligase parkin (PARK2), IRGM, and autophagy-related proteins 16-1 (ATG16L1), are associated with susceptibility to mycobacterial disease (Yang et al., 2014; Capela et al., 2016; Uaska Sartori Priscila et al., 2020). A single nucleotide polymorphism (SNP) in PARK2 correlates significantly with increased susceptibility to M. ulcerans infection, while an SNP in NOD2 is associated with increased disease progression. Conversely, an SNP in ATG16L1 protects against severe disease during $M$. ulcerans infection (Capela et al., 2016; Manry et al., 2020). Although not directly associated with autophagy, other SNPs in iNOS and IFN- $\gamma$ have been associated with increased susceptibility to Buruli Ulcer, leprosy, and TB (Bibert et al., 2017).

The major virulence factor of $M$. ulcerans is mycolactone, a cytotoxic, immunosuppressive polyketide-derived macrolide. Mycolactone alone induces autophagy, although it impairs autophagy flux (Gama et al., 2014). The induction of autophagy is further evidenced by mycolactone's ability to inhibit mTOR, thereby resulting in the upregulation of apoptosis activating protein, Bim (Bieri et al., 2017). This pathway signals through the inactivation of Akt by an alternative mTOR pathway. As such, activation of mTOR could lead to inhibition of Bim and, subsequently, apoptosis, resulting in control of bacterial infection. 
Two variants of $M$. abscessus and M. fortuitum are frequently observed: rough (R) and smooth (S) (Byrd and Lyons, 1999; Catherinot et al., 2007; Lee et al., 2016). It is widely accepted that the $\mathrm{R}$ variant is hypervirulent compared to its $\mathrm{S}$ counterpart. It is known that the loss of glycopeptidolipid (GPL) is the cause of the S-variant of $M$. abscessus in several animal models (Byrd and Lyons, 1999; Catherinot et al., 2007). A highly virulent clinical isolate of $M$. abscessus-R significantly inhibited autophagic flux than the $\mathrm{S}$ variant of $M$. abscessus. The $\mathrm{R}$ variant's intracellular survival is enhanced considerably by blocking the autophagosome-lysosome fusion in macrophages compared to the S variant (Kim et al., 2017c). These immunological effects of NTMs have been mostly studied from the perspective of respiratory illness and genome comparison studies focusing on traditional virulence factors for related opportunistic pathogens (N'Goma et al., 2015) indicates we have only a minimal understanding of their impact during ulcerative infection.

Whereas M. abscessus S utilizes phosphatidyl-myoinositol to mask TLR2 activation, $M$. fortuitum $\mathrm{R}$ does not induce the antiinflammatory molecule TNFAIP3 (Lee et al., 2016). TNFAIP3 is an anti-apoptotic molecule that inhibits NF- $\kappa \mathrm{B}$ and TNF-induced cell death (Lee et al., 2000). TNF- $\alpha$ and the TLR2 signaling pathway appear to play an essential role in M. fortuitum infection. Some lipids of RGMs have differential terminal modifications compared to those from pathogenic slow-growing mycobacteria. Specifically, lipoarabinomannan (LAM) in RGM is capped with phosphomyo-inositol (PI) caps compared to mannose (Man) caps in pathogenic mycobacteria. Purified PI-LAM induces significantly more apoptosis than purified Man-LAM in a TLR2 dependent manner (Bohsali et al., 2010). Similarly, PILAM caused significant autophagy induction, unlike ManLAM, which did not induce autophagy (Shui et al., 2011; Singh et al., 2019). Although terminal modifications of LAM appear to play a role in the modulation of apoptosis, total lipid from both pathogenic and non-pathogenic mycobacteria can induce autophagy (Zullo et al., 2014; Kim et al., 2017c; Mishra et al., 2019). Interestingly, while total lipids from $M$. abscessus-R induce a significant autophagy level, live $M$. marinum induces autophagy and simultaneously inhibits autophagy flux, which leads to increased intracellular survival (Lerena and Colombo, 2011; Kim et al., 2017c; Oliveira et al., 2020; Pohl et al., 2020).

It has been known for many years that autophagy is an efficient mechanism to clear $M$. leprae from macrophages (Evans and Levy, 1972). However, it has been recently described that autophagy may be a major modulating factor in leprosy disease presentation. In patients presenting with multibacillary leprosy, there is significantly less autophagic control in macrophages taken from patient lesions than patients presenting with paucibacillary tuberculoid leprosy (Silva et al., 2017a). This supports previous studies which found that the autophagy inhibiting cytokine IL-10 is predominant in multibacillary leprosy compared to high levels of IL26 , IFN- $\gamma$, and TNF- $\alpha$, autophagy inducing cytokines, found during paucibacillary tuberculoid leprosy (Yamamura, 1992; Sieling and Modlin, 1994; Nath, 2016; Dang et al., 2019). Multibacillary leprosy patients who developed type 1 reaction (T1R) episodes demonstrated dysregulation of autophagy genes and significantly increased expression of the mTOR complex leading to overexpression of the NLRP3-inflammasome-IL-1B pathway. These data demonstrate that leprosy treatment with pro-autophagic drugs may improve treatment outcomes by reducing reversal reaction risk (de Mattos Barbosa et al., 2018).

The establishment of uncontrolled mycobacterial infection in an extracellular bacterial milieu or biofilm presents significant complications for treatment (Greendyke and Byrd, 2008). Many mycobacterial species causing ulcerative diseases are widely considered to have significantly reduced sensitivity to antibiotics and a natural ability to acquire antibiotic resistance, making it very hard to treat and leading to high failure rates (Moore and Frerichs, 1953; Jarlier and Nikaido, 1990; Sanguinetti et al., 2001; Nessar et al., 2012). Utilizing host-directed therapies, such as those inducing autophagy, to inhibit bacterial release from the cell and form biofilms or bacterial milieus may enhance the efficacy of currently available antibiotics.

\section{HARNESSING AUTOPHAGY TO FIGHT MYCOBACTERIA}

\section{Targeting Autophagy to Treat a Mycobacterial Infection}

Rapamycin has been the most frequently used autophagyinducing drug for host-directed therapies. While Rapamycin appears to improve pathology during $M t b$ infection, there is evidence that it is directly antimycobacterial in vitro at the high concentration used for the reported studies. Rapamycin does not seem to have a direct effect on $M$. smegmatis or BCG for short periods. Still, it was found to significantly inhibit BCG, M. kansasii, M. avium, and multiple virulent $M t b$ strains over 7-8 days incubation (Greenstein et al., 2008; Zullo et al., 2014). This direct antimycobacterial activity is somewhat unsurprising as Rapamycin was initially discovered as a novel antifungal antibiotic (Singh et al., 1979). Rapamycin is not the only drug evaluated as a host-directed therapy for the treatment of tuberculosis. Some medications, such as azithromycin and metformin, have been found to decrease mycobacterial infections in patients with cystic fibrosis and diabetes due to their ability to increase the autophagic clearance of bacteria (Renna et al., 2011; Tseng, 2018). Table 1 summarizes the drugs and compounds that have been tested for their ability to induce autophagy and treat mycobacterial diseases.

Of importance, the use of Rapamycin to treat infectious diseases is not practical due to its immunosuppressant actions. Gupta et al. (2014) have attempted to address this issue with the administration of Rapamycin by microparticles directly to the airway. Highlighting the delicate balance needed for host-directed therapies, the study found that the induction of autophagy in the lung macrophages was inverse to the dosing interval. In vitro and in vivo rapamycin microparticles induce autophagolysosomal formation in macrophages infected with $M t b$ in an mTOR-dependent manner (Gupta et al., 2014; Gupta et al., 2016). Rapamycin alone significantly improved pathology during $M t b$ infection in a mouse model but did 
TABLE 1 | Summary of current experimental treatments inducing autophagy during M. tuberculosis infection.

\begin{tabular}{|c|c|c|c|}
\hline Drug & Model & Mode & References \\
\hline $\begin{array}{l}\text { Small Molecule Enhancers of } \\
\text { Rapamycin }\end{array}$ & M. bovis BCG infection of primary human macrophages & Induce autophagy independently of mTOR & Floto et al., 2007 \\
\hline Rifampicin & Mtb infection of human differentiated monocytes & Increased autolysosome formation, directly antimycobacterial & Genestet et al., 2018 \\
\hline Linezolid & Mtb infection of human differentiated monocytes & Increased autophagosomes production, directly antimycobacterial & Genestet et al., 2018 \\
\hline Bedaquiline & Mtb infection of human differentiated monocytes & Increased autophagosomes production, directly antimycobacterial & Genestet et al., 2018 \\
\hline Nitazoxanide & $\begin{array}{l}\text { Mtb infection of human differentiated monocytes. M. leprae } \\
\text { infection of mice }\end{array}$ & $\begin{array}{l}\text { Increased autophagy by inhibition of NADPH quinone } \\
\text { oxidoreductase } 1 \text { leading to mTOR inhibition by TSC2 }\end{array}$ & $\begin{array}{l}\text { Lam et al., 2012; Bailey } \\
\text { et al., } 2017\end{array}$ \\
\hline Baicalin & Mtb infection of mouse macrophages & $\begin{array}{l}\text { Induce autophagy via the PI3K/Akt/mTOR pathway, inhibit NLRP3 } \\
\text { inflammasome activation via the PI3K/Akt/NF-kB, reduction of } \\
\text { proinflammatory cytokines }\end{array}$ & $\begin{array}{l}\text { Lin et al., 2013; Zhang } \\
\text { et al., } 2017\end{array}$ \\
\hline Vitamin D & Mtb/HIV co-infection model of primary human macrophages & Cathelicidin dependent induction of autophagy & $\begin{array}{l}\text { Liu et al., 2007; Martineau } \\
\text { et al., 2007; Yuk et al., } \\
\text { 2009; Jo, 2010; Campbell } \\
\text { and Spector, 2012b }\end{array}$ \\
\hline 4-phenylbutyrate & Mtb infection of human monocytes & $\begin{array}{l}\text { Induction of LL-37 promoting autophagy via P2RX7 receptor, } \\
\text { increasing free } \mathrm{Ca}^{2+} \text { and activation of AMPK and Ptdlns3K } \\
\text { pathway. }\end{array}$ & Rekha et al., 2015 \\
\hline Gefitinib & Mtb infection of murine bone marrow-derived macrophages & $\begin{array}{l}\text { STAT3 dependent cytokine responses, increasing lysosomal } \\
\text { trafficking }\end{array}$ & $\begin{array}{l}\text { Stanley et al., 2014; Sogi } \\
\text { et al., } 2017\end{array}$ \\
\hline Carbamazepine & $\begin{array}{l}\text { Mtb infection of human-derived macrophages or murine } \\
\text { alveolar macrophages. M. marinum zebrafish model of } \\
\text { infection. MDR Mtb infection of C57BL/6 mice }\end{array}$ & $\begin{array}{l}\text { Induce autophagy by blocking myoinositol uptake, decreasing } \\
\text { phosphatidylinositol, and activating AMP kinase in an mTOR } \\
\text { independent manner. }\end{array}$ & $\begin{array}{l}\text { Schiebler et al., 2015; } \\
\text { Juárez et al., } 2016\end{array}$ \\
\hline Valproic acid & $\begin{array}{l}\text { Mtb infection of human-derived macrophages or murine } \\
\text { alveolar macrophages }\end{array}$ & Increases colocalization of LC3 with Mtb & $\begin{array}{l}\text { Schiebler et al., 2015; } \\
\text { Juárez et al., } 2016\end{array}$ \\
\hline Loperamide & $\begin{array}{l}\text { Mtb infection of human-derived macrophages or murine } \\
\text { alveolar macrophages }\end{array}$ & $\begin{array}{l}\text { Increases colocalization of LC3 with Mtb and reduces TNF- } \alpha \\
\text { production }\end{array}$ & Juárez et al., 2016 \\
\hline Simvastatin & Mtb infection of C57BL/6 mice & $\begin{array}{l}\text { Reduction of membrane cholesterol levels promotes phagosomal } \\
\text { maturation and autophagy }\end{array}$ & Parihar et al., 2013 \\
\hline Metformin & Mtb infection of C57BL/6 mice & $\begin{array}{l}\text { Induction of mitochondrial reactive oxygen species, AMPK } \\
\text { activation, and autophagy induction }\end{array}$ & $\begin{array}{l}\text { Singhal et al., 2014; } \\
\text { Restrepo, } 2016\end{array}$ \\
\hline Trehalose & $\begin{array}{l}\text { Mtb/M. avium/M. fortuitum infection of human differentiated } \\
\text { monocytes }\end{array}$ & $\begin{array}{l}\text { Increase autophagy flux through activation of ptdlns } 3 \text { P by activation } \\
\text { of PIKFYVE }\end{array}$ & $\begin{array}{l}\text { Sarkar et al., 2007; Sharma } \\
\text { et al., } 2020\end{array}$ \\
\hline Mycobacterial PILAM & Mtb infection of murine macrophages & $\begin{array}{l}\text { Induction of autophagy and pro-inflammatory cytokines, enhanced } \\
\text { colocalization of Mtb with phagolysosomes }\end{array}$ & $\begin{array}{l}\text { Shui et al., 2011; Singh } \\
\text { et al., } 2019\end{array}$ \\
\hline Nordi-hydroguaiaretic acid & Avirulent Mtb infection of human differentiated monocytes & $\begin{array}{l}\text { Directly antimycobacterial, induce autophagosome formation and } \\
\text { colocalization with } M \text { tb }\end{array}$ & $\begin{array}{l}\text { Guzmán-Beltrán et al., } \\
2016\end{array}$ \\
\hline Lactoferricin peptides & M. avium infection of murine bone marrow macrophages & Increased autophagosome formation & Silva et al., 2017b \\
\hline
\end{tabular}


not clear bacteria. Co-administration of isoniazid and rifabutin with Rapamycin microparticles considerably improved bacterial clearance (Gupta et al., 2014, 2016). As the administration of microparticles with autophagy-inducing drugs may improve traditional antimycobacterial chemotherapies, an alternative strategy is utilizing microparticles that directly induce autophagy. Poly (lactic-co-glycolic acid) microparticles were found to be antimycobacterial in human macrophages. For example, NFкB activity was increased during microparticle treatment, and antimycobacterial effects were reversed by autophagy inhibitors (Lawlor et al., 2016).

An antiprotozoal drug, nitazoxanide, has been extensively tested to treat $M t b$ and NTMs alone and in conjunction with traditional antimycobacterial medicines. These conventional antibiotics were not found to inhibit autophagosome formation stimulated by nitazoxanide (Lam et al., 2012). Nitazoxanide has been previously explored as an autophagy agonist for treating multiple disease states such as Alzheimer's and cancer (Di Santo and Ehrisman, 2014; Li et al., 2020). It has also been examined as a potential treatment option against several mycobacteria including M. leprae (Bailey et al., 2017) and MAC (Rossignol, 1999). Nitazoxanide is metabolized into hydroxylamine by mycobacterial nitroreductase NfnB (Buchieri et al., 2017). Interestingly, nitazoxanide can kill replicating and non-replicating mycobacteria, emphasizing its potential role in combating latent mycobacterial infection (de Carvalho et al., 2009; Iacobino et al., 2019). Like Rapamycin and nitazoxanide, metformin also increases bacterial clearance during traditional anti-mycobacterial treatment, while inducing autophagy (Singhal et al., 2014; Lachmandas et al., 2019).

Two of the most promising experimental host-directed therapies against $M$. tuberculosis are Vitamin D3 and Metformin (Naicker et al., 2020). Metformin was shown to increase mitochondrial reactive oxygen species production, acting through AMPK, leading to control of drug-resistant $M t b$ and facilitation of phagolysosome fusion (Singhal et al., 2014; Yew et al., 2020). There also appears to be a correlation between metformin treatment for diabetes mellitus type II and delayed smear and culture conversion and reduced unfavorable outcomes (Singhal et al., 2014; Degner et al., 2017; Marupuru et al., 2017; Lee et al., 2018; Padmapriyadarsini et al., 2019). While metformin shows promise in preventing TB in type II diabetes patients, Vitamin D supplementation showed no improvement in TB treatment outcomes in patients with vitamin D sufficiency during drug sensitive $M t b$ infection. However, vitamin D deficiency is associated with an increased risk of $M t b$ infection (Ustianowski et al., 2005; Chun et al., 2011). Vitamin D supplementation did reduce the time to sputum culture conversion in patients with Taql vitamin $\mathrm{D}$ receptor gene polymorphism, indicating that Vitamin D does play an important role in TB treatment outcomes. Vitamin D supplementation also improved the MDRTB sputum culture conversion rate (Zhang et al., 2019). In vitro treatment with vitamin $\mathrm{D}$ during $\mathrm{HIV}$ and $M t b$ co-infection or $M t b$ infection alone concluded that autophagy induction was responsible for the better control of both HIV and $M t b$ in macrophages (Yuk et al., 2009; Fabri et al., 2011; Campbell and Spector, 2012a).
Many host pathways may constitute viable targets for hostdirected therapies (HDTs). Apoptosis and autophagy have been the most explored HDT targets of $M t b$ and NTMs. Even though apoptosis may be a possible target, there is mounting evidence that NTMs can escape apoptotic bodies to ensure survival and disease progression (Early et al., 2011; Bento et al., 2020). Autophagy presents an exciting target as the induction of autophagy promotes bacterial clearance and antigen presentation (Castillo et al., 2012; Saini et al., 2016). The current recommended treatment for NTM infection is clarithromycin or azithromycin, ethambutol, and rifamycin (Griffith, 2018; Griffith, 2019; Daley et al., 2020; Gopalaswamy et al., 2020). Azithromycin was shown to inhibit autophagosome maturation resulting in an increased risk of $M$. abscessus infection (Renna et al., 2011; Torfs et al., 2019). It has also been found that many traditional anti-mycobacterials, though directly antimycobacterial, also have off-target effects that promote autophagy (Kim et al., 2012; Zullo and Lee, 2012b). Unfortunately, the development of new drugs targeting particular host pathways is often slow and expensive. One potential strategy to expedite this drug discovery is studying and assessing previous medications known to increase autophagy and their effect on mycobacteria (Williams et al., 2008; Sundaramurthy et al., 2013; Stanley et al., 2014; Kim et al., 2019). Potentially repurposed autophagy targeting host-directed therapies are summarized in Table 2. Many of these drugs are of interest because of the modulation of the host immune response. Accordingly, they should also be effective against a broad range of mycobacteria and other intracellular pathogens.

As a better understanding of the role of infection-induced autophagy transpires, more targeted host-directed therapy approaches can be developed and exploited. With $\mathrm{C}_{4} \mathrm{~T}_{4}$ (a TLR4 agonist), autophagy was induced in guinea pigs infected with $M t b$ in a CLEC4E-dependent manner through MYD88 and PrdIns3K activation, leading to reduced mycobacterial burden (Pahari et al., 2020). Along with targeting cell receptors to activate autophagy, there is increasing evidence that many microRNAs (miRNAs) can be targeted to activate autophagy during mycobacterial infection (Wang et al., 2013; Kim et al., 2015, 2017a,b; Kumar et al., 2016; Etna et al., 2018; Liu et al., 2018; Li et al., 2019). These miRNAs modulate autophagy through different upstream pathways of mTOR. Mtb infection induces miRNA-144, which targets the DNA damage regulated autophagy modulator 2 (DRAM2), resulting in autophagy inhibition through AMPK (Kim et al., 2017b). Similar to targeting CLEC4E through TLR4 agonists, TLR2 and MYD88 are required to induce miRNA-125a during $M t b$ infection. Mtb induces expression of miR-125a in macrophages, which results in the inhibition of autophagy by targeting UV radiation resistance-associated gene (UVRAG) in the AMPK dependent manner (Kim et al., 2015).

\section{Targeting Autophagy to Prevent Mycobacterial Infection}

BCG is widely used as a vaccine against tuberculosis. BCG evades phagosome maturation, autophagy, MHC-II expression of antigen-presenting cells (APCs), and T-cell activation (Deretic et al., 1997; Singh et al., 2006; Münz, 2016; Saini et al., 2016; 
Khan et al., 2019). Clinical isolates of $M t b$ that could not inhibit autophagy showed increased TB disease outcomes and the extent of disease ( $\mathrm{Li}$ et al., 2016), strongly indicating that autophagy is a crucial host pathway for the control of TB. The ability to utilize this essential host pathway could prove a viable avenue for improving mycobacterial vaccines (Yuk and Jo, 2014; Flores-Valdez et al., 2018; Tao and Drexler, 2020). Notably, the yellow fever vaccine, YF-17D, one of the most successful vaccines, has been found to enhance autophagydependent antigen presentation. The mechanisms of the vaccine efficacy by YF-17D were not well understood until its role in autophagy modulation was deciphered (Ravindran et al., 2014).

Developing new vaccines or improving the BCG by harnessing autophagy is an area of interest and has garnered examination. BCG, like $M t b$, expresses a wide array of bacterial effectors that modulate autophagy, but co-immunization of mice with BCG and rapamycin-treated dendritic cells enhanced Th1mediated protection against $M t b$ infection (Jagannath et al., 2009). Similarly, it was demonstrated that a recombinant BCG expressing $85 \mathrm{C} 5\left(\mathrm{BCG}^{85 C 5}\right)$ induced a robust MHC-IIdependent antigen presentation to $\mathrm{CD}^{+} \mathrm{T}$ cells in vitro. The 85C5 peptide contains the TLR-2 activating C5 peptide from $M t b$ CFP-10 protein. The vaccine also elicited stronger Th1 cytokines from APCs of C57Bl/6 mice and enhanced MHC-II surface expression on macrophages by inhibiting the membrane associated RING-CH 1 (MARCH1) E3 ligase that degrades MHC-II. BCG ${ }^{85 C 5}$ infected APCs presented antigens in a MyD88 or a TLR-2 dependent manner (Khan et al., 2019). Additionally, activation of TLR3 or TLR4 by LPS cleared mycobacteria in vitro in an autophagy-dependent way (Xu et al., 2007, 2013).

BCG was genetically modified to improve its immunogenicity by replacing the urease $\mathrm{C}$ encoding gene with the listeriolysin encoding gene from Listeria monocytogenes (Nieuwenhuizen et al., 2017). Listeriolysin perturbates the phagosomal membrane at acidic $\mathrm{pH}$ and Urease $\mathrm{C}$ neutralize the phagosome harboring BCG. Deletion of ureC leads to rapid phagosome acidification and promotes phagolysosome fusion. Subsequently, BCG $\Delta$ ureC:hly elevates apoptosis and autophagy and accelerates release of mycobacterial antigens into the cytosol. The BCG $\Delta$ ureC:hly vaccine completed phase I and IIa clinical trials. Upon deleting the anti-apoptotic gene nuoG to enhance cross protection, BCG $\Delta$ ureC:hly $\Delta$ nuo $G$ vaccine showed reduced $M t b$ burden in the lungs of mice leading to less pathology and, most importantly, enhanced immune responses. It was found that the nuoG deletion leads to significant induction of autophagy and an improved safety profile (Gengenbacher et al., 2016). M. indicus pranii is another potential immunotherapy and vaccine candidate under clinical trials (Gupta et al., 2012; Saqib et al., 2016; Sharma et al., 2017). Boosting BCG vaccination with $M$. indicus pranii resulted in improved protection in a murine model of $M t b$ infection. Increased IFN- $\gamma$, IL-12, and IL-17 were observed along with increased polyfunctional T cells (Saqib et al., 2016). This increased protection and immune response were subsequently due to increased autophagy induced by $M$. indicus pranii, potentially due to its PILAM (Singh et al., 2017, 2019).

While improving the BCG vaccine appears a viable short-term solution to improve vaccine efficacy against $M t b$, the efforts 
to develop new vaccines must be continued. BCG is a live attenuated vaccine, but it is not suitable for use in all cases. The development of other vaccine options, such as DNA vaccines or subunit vaccines, would significantly advance the vaccination strategy against $M t b$ and NTMs. A DNA vaccine encoding for the potent $M t b$ antigen 85B (Ag85B) significantly enhanced autophagy activation and vaccine efficacy when delivered with a plasmid encoding a kinase defective (mTOR-KD) (Meerak et al., 2013). This mTOR-KD DNA vaccine-elicited considerably higher Ag85B-specific antibodies, increased secretion of IFN- $\gamma$ and IL2 levels, and enhanced proliferation of $\mathrm{CD} 4^{+} \mathrm{T}$ cells. Similar to this approach, it was found that an LC3-LpqH-Ag85B DNA vaccination reduced mycobacterial burden, increased IFN- $\gamma$ and IL-2, and enhanced the Th1 immune response (Hu et al., 2014).

Adjuvating or boosting BCG with autophagy-inducing substrates has also been examined as a potential way to increase the efficacy of current vaccines. Curcumin-coated nanoparticles have been found to enhance autophagy, leading to increased Th1 and Th17 central memory $\mathrm{T}$ cells (Ahmad et al., 2019). Other studies have identified autophagy as having an essential role in forming and surviving memory $\mathrm{T}$ cells (Xu et al., 2014). Like curcumin nanoparticles, boosting BCG vaccine with nanofibers acting through the autophagy pathway improved BCG efficacy (Rudra et al., 2017; Chesson et al., 2018). While some DNA vaccines directly target autophagy, the development of an adjuvant system targeting autophagy may improve the efficacy of potential subunit vaccines. Utilizing the lactic acid bacteria (LAB) as an adjuvant for $M t b$ antigens showed improved IFN- $\gamma$ and NO responses, polarizing a Th1 response and increasing autophagosome formation. Although LAB's protective efficacy was not tested, these improved immunological responses compared to $M t b$ antigen alone are promising (Ghadimi et al., 2010).

\section{CONCLUSION}

Autophagy has been established as an effective mechanism for the clearance of mycobacteria from the infected macrophages. Many studies have looked at the potential of autophagy-inducing drugs to improve current treatment regimens against mycobacteria. Due to the dramatic rise of antibiotic-resistant mycobacteria and the upsurge of NTMs that are intrinsically resistant to traditional antibiotics, host-directed therapies are even more relevant (Deretic, 2008; Kim et al., 2012; Zullo and Lee, 2012b; Kim et al., 2019; Bento et al., 2020).

While $M t b$ inhibits apoptosis for bacterial survival (Hinchey et al., 2007), NTMs utilize the hosts' cellular progression from apoptosis to secondary necrosis (Gao and Kwaik, 2000; Lee et al., 2011) or induce membrane perforation (similar to that

\section{REFERENCES}

Ahmad, S., Bhattacharya, D., Kar, S., Ranganathan, A., Van Kaer, L., and Das, G. (2019). Curcumin Nanoparticles Enhance Mycobacterium bovis BCG Vaccine Efficacy by Modulating Host Immune Responses. Infect. Immun. 87, e291-e219. doi: 10.1128/iai.00291-19 observed during necrosis) to allow for bacterial escape and communication (Roux et al., 2016). Subsequent expression of bacterial factors that form an extracellular milieu or biofilm makes control by either phagocytic cells or administered antibiotics much more difficult. If host-directed therapies inhibiting apoptosis or inducing autophagy could be employed against these non-tuberculosis mycobacteria, infection control of the contained intracellular mycobacteria with traditional antibiotics may be far more successful. Additionally, it has been demonstrated that potent autophagy-inducing chemicals could increase mycobacterial clearance from macrophages, like seen during rapamycin treatment (Singh et al., 2017).

Autophagy-targeting host-directed therapies and vaccines for mycobacteria have numerous potential benefits. However, further understanding of the role of autophagy, its molecular mechanisms, and regulation during mycobacterial infection is required to develop persistent, viable, and safe host-directed therapies and vaccines. Additionally, examination of the crosstalk between autophagy and apoptosis during infection should significantly improve our understanding of the applicability of these host pathways as a viable target for treatment. Though host-directed therapies may play a vital role for intrinsically antibiotic-resistant NTMs and drug-resistant TB, they will need to be considered together with traditional anti-mycobacterial medicines, with the goal of shorter treatment times and improved outcomes.

\section{AUTHOR CONTRIBUTIONS}

ES and SL conceived the review. ES wrote the first draft of the manuscript. SL wrote sections of the manuscript and provided overall editing. All authors contributed to manuscript revision, read, and approved the submitted version.

\section{FUNDING}

This research was supported by the National Institute of Allergy and Infectious Diseases (R01 AI127711). The funders had no role in study design, data collection, interpretation, or the decision to submit the work for publication.

\section{ACKNOWLEDGMENTS}

Figure 1 was created with BioRender.com. The authors acknowledge and thank the kind contributions and discussion of Maria González Orozco and Jia Wang (University of Texas Medical Branch).

Axe, E. L., Walker, S. A., Manifava, M., Chandra, P., Roderick, H. L., Habermann, A., et al. (2008). Autophagosome formation from membrane compartments enriched in phosphatidylinositol 3-phosphate and dynamically connected to the endoplasmic reticulum. J. Cell Biol. 182, 685-701. doi: 10.1083/jcb.200803137

Bailey, M. A., Na, H., Duthie, M. S., Gillis, T. P., Lahiri, R., and Parish, T. (2017). Nitazoxanide is active against Mycobacterium 
leprae. PLoS One 12:e184107. doi: 10.1371/journal.pone. 0184107

Balcewicz-Sablinska, M. K., Keane, J., Kornfeld, H., and Remold, H. G. (1998). Pathogenic Mycobacterium tuberculosis Evades Apoptosis of Host Macrophages by Release of TNF-R2, Resulting in Inactivation of TNF- $\alpha$. J. Immunol. 161, 2636-2641.

Bento, C. M., Gomes, M. S., and Silva, T. (2020). Looking beyond Typical Treatments for Atypical Mycobacteria. Antibiotics 9:18.

Bermudez, L. E., Inderlied, C. B., Kolonoski, P., Chee, C. B., Aralar, P., Petrofsky, M., et al. (2012). Identification of (+)-Erythro-Mefloquine as an Active Enantiomer with Greater Efficacy than Mefloquine against Mycobacterium avium Infection in Mice. Antimicrob. Agents Chemother. 56, 4202-4206. doi: 10.1128/aac.00320-12

Bermudez, L. E., Kolonoski, P., Wu, M., Aralar, P. A., Inderlied, C. B., and Young, L. S. (1999). Mefloquine Is Active In Vitro and In Vivo against Mycobacterium avium Complex. Antimicrob. Agents Chemother. 43, 1870-1874. doi: 10.1128/ aac. 43.8 .1870

Bibert, S., Bratschi, M. W., Aboagye, S. Y., Collinet, E., Scherr, N., Yeboah-Manu, D., et al. (2017). Susceptibility to Mycobacterium ulcerans Disease (Buruli ulcer) Is Associated with IFNG and iNOS Gene Polymorphisms. Front. Microbiol. 8:1903. doi: $10.3389 /$ fmicb. 2017.01903

Bieri, R., Scherr, N., Ruf, M.-T. S., Dangy, J.-P., Gersbach, P., Gehringer, M., et al. (2017). The Macrolide Toxin Mycolactone Promotes Bim-Dependent Apoptosis in Buruli Ulcer through Inhibition of mTOR. Am. Chem. Soc. Chem. Biol. 12, 1297-1307. doi: 10.1021/acschembio.7b00053

Bodle, E. E., Cunningham, J. A., Della-Latta, P., Schluger, N. W., and Saiman, L. (2008). Epidemiology of Nontuberculous Mycobacteria in Patients without HIV Infection. Emerg. Infect. Dis. 14, 390-396. doi: 10.321/eid1403.061143

Bohsali, A., Abdalla, H., Velmurugan, K., and Briken, V. (2010). The nonpathogenic mycobacteria $M$. smegmatis and $M$. fortuitum induce rapid host cell apoptosis via a caspase-3 and TNF dependent pathway. BMC Microbiol. 10:237. doi: $10.1186 / 1471-2180-10-237$

Brüning, A., Brem, G. J., Vogel, M., and Mylonas, I. (2014). Tetracyclines cause cell stress-dependent ATF4 activation and mTOR inhibition. Exp. Cell Res. 320, 281-289. doi: 10.1016/j.yexcr.2013.11.012

Buchieri, M. V., Cimino, M., Rebollo-Ramirez, S., Beauvineau, C., Cascioferro, A., Favre-Rochex, S., et al. (2017). Nitazoxanide Analogs Require Nitroreduction for Antimicrobial Activity in Mycobacterium smegmatis. J. Med. Chem. 60, 7425-7433. doi: 10.1021/acs.jmedchem.7b00726

Byrd, T. F., and Lyons, C. R. (1999). Preliminary characterization of a Mycobacterium abscessus mutant in human and murine models of infection. Infect. Immun. 67, 4700-4707.

Campbell, G. R., and Spector, S. A. (2012a). Autophagy induction by vitamin D inhibits both Mycobacterium tuberculosis and human immunodeficiency virus type 1. Autophagy 8, 1523-1525. doi: 10.4161/auto.21154

Campbell, G. R., and Spector, S. A. (2012b). Vitamin D Inhibits Human Immunodeficiency Virus Type 1 and Mycobacterium tuberculosis Infection in Macrophages through the Induction of Autophagy. PLoS Pathogens 8:e1002689. doi: 10.1371/journal.ppat.1002689

Capela, C., Dossou, A. D., Silva-Gomes, R., Sopoh, G. E., Makoutode, M., Menino, J. F., et al. (2016). Genetic Variation in Autophagy-Related Genes Influences the Risk and Phenotype of Buruli Ulcer. PLoS Neglec. Trop. Dis. 10:4671. doi: 10.1371/journal.pntd.0004671

Castillo, E. F., Dekonenko, A., Arko-Mensah, J., Mandell, M. A., Dupont, N., Jiang, S., et al. (2012). Autophagy protects against active tuberculosis by suppressing bacterial burden and inflammation. Proc. Natl. Acad. Sci. U S A 109, E3168E3176. doi: 10.1073/pnas.1210500109

Catherinot, E., Clarissou, J., Etienne, G., Ripoll, F., Emile, J.-F., Daffe, M., et al. (2007). Hypervirulence of a Rough Variant of the Mycobacterium abscessus Type Strain. Infect. Immun. 75, 1055-1058. doi: 10.1128/IAI.00835-06

Chai, Q., Wang, X., Qiang, L., Zhang, Y., Ge, P., Lu, Z., et al. (2019). A Mycobacterium tuberculosis surface protein recruits ubiquitin to trigger host xenophagy. Nat. Commun. 10:1973.

Chandra, P., Ghanwat, S., Matta, S. K., Yadav, S. S., Mehta, M., Siddiqui, Z., et al. (2015). Mycobacterium tuberculosis Inhibits RAB7 Recruitment to Selectively Modulate Autophagy Flux in Macrophages. Sci. Rep. 5:16320. doi: 10.1038/ srep 16320
Chesson, C. B., Huante, M., Nusbaum, R. J., Walker, A. G., Clover, T. M., Chinnaswamy, J., et al. (2018). Nanoscale Peptide Self-assemblies Boost BCGprimed Cellular Immunity Against Mycobacterium tuberculosis. Sci. Rep. 8:12519. doi: 10.1038/s41598-018-31089-y

Choy, A., Dancourt, J., Mugo, B., O'Connor, T. J., Isberg, R. R., Melia, T. J., et al. (2012). The Legionella Effector RavZ Inhibits Host Autophagy Through Irreversible Atg8 Deconjugation. Science 338, 1072-1076. doi: 10.1126/science. 1227026

Chu, C.-W., Ko, H.-J., Chou, C.-H., Cheng, T.-S., Cheng, H.-W., Liang, Y.-H., et al. (2019). Thioridazine Enhances P62-Mediated Autophagy and Apoptosis Through Wnt/B-Catenin Signaling Pathway in Glioma Cells. Int. J. Mole. Sci. 20:473.

Chun, R. F., Adams, J. S., and Hewison, M. (2011). Immunomodulation by vitamin D: implications for TB. Exp. Rev. Clin. Pharmacol. 4, 583-591. doi: 10.1586/ecp. 11.41

Conrad, W. H., Osman, M. M., Shanahan, J. K., Chu, F., Takaki, K. K., Cameron, J., et al. (2017). Mycobacterial ESX-1 secretion system mediates host cell lysis through bacterium contact-dependent gross membrane disruptions. Proc. Natl. Acad. Sci. 114, 1371-1376. doi: 10.1073/pnas.1620133114

Converse, P. J., Almeida, D. V., Tyagi, S., Xu, J., and Nuermberger, E. L. (2019). Shortening Buruli Ulcer Treatment with Combination Therapy Targeting the Respiratory Chain and Exploiting Mycobacterium ulcerans Gene Decay. Antimicrob. Agents Chemother. 63, e426-e419. doi: 10.1128/aac.00426-19

Cooper, A. M., Dalton, D. K., Stewart, T. A., Griffin, J. P., Russell, D. G., and Orme, I. M. (1993). Disseminated Tuberculosis in Interferon- $\gamma$ Gene-disrupted Mice. J. Exp. Med. 178, 2243-2247. doi: 10/1084/jem.178.6.2243

Daley, C. L., Iaccarino, J. M., Lange, C., Cambau, E., Wallace, R. J. Jr., Andrejak, C., et al. (2020). Treatment of Nontuberculous Mycobacterial Pulmonary Disease: An Official ATS/ERS/ESCMID/IDSA Clinical Practice Guideline. Clin. Infect. Dis. 71, e1-e36. doi: 10.1093/cid/ciaa241

Dang, A. T., Teles, R. M. B., Weiss, D. I., Parvatiyar, K., Sarno, E. N., Ochoa, M. T., et al. (2019). IL-26 contributes to host defense against intracellular bacteria. J. Clin. Invest. 129, 1926-1939. doi: 10.1172/JCI99550

D’Cruze, T., Gong, L., Treerat, P., Ramm, G., Boyce, J. D., Prescott, M., et al. (2011). Role for the Burkholderia pseudomallei Type Three Secretion System Cluster 1 bpscN Gene in Virulence. Infect. Immun. 79, 3659-3664. doi: 10.1128/iai. 01351-10

de Carvalho, L. P. S., Lin, G., Jiang, X., and Nathan, C. (2009). Nitazoxanide Kills Replicating and Nonreplicating Mycobacterium tuberculosis and Evades Resistance. J. Med. Chem. 52, 5789-5792. doi: 10.1021/jm9010719

De Groote, M. A., and Huitt, G. (2006). Infections Due to Rapidly Growing Mycobacteria. Clin. Dis. 42, 1756-1763. doi: 10.1086/504381

de Mattos Barbosa, M. G., de Andrade Silva, B. J., Assis, T. Q., da Silva, Prata, R. B., Ferreira, H., et al. (2018). Autophagy Impairment Is Associated With Increased Inflammasome Activation and Reversal Reaction Development in Multibacillary Leprosy. Front. Immunol. 9:1223. doi: 10.3389/fimmu.2018. 01223

Degner, N. R., Wang, J.-Y., Golub, J. E., and Karakousis, P. C. (2017). Metformin Use Reverses the Increased Mortality Associated With Diabetes Mellitus During Tuberculosis Treatment. Clin. Infect. Dis. 66, 198-205. doi: 10.1093/cid/cix819

Deng, W., Long, Q., Zeng, J., Li, P., Yang, W., Chen, X., et al. (2017). Mycobacterium tuberculosis PE_PGRS41 Enhances the Intracellular Survival of M. smegmatis within Macrophages Via Blocking Innate Immunity and Inhibition of Host Defense. Sci. Rep. 7:46716. doi: 10.1038/srep46716

Deretic, V. (2008). Autophagy, an immunologic magic bullet: Mycobacterium tuberculosis phagosome maturation block and how to bypass it. Future Microbiol. 3, 517-524. doi: 10.2217/17460913.3.5.517

Deretic, V., Via, L. E., Fratti, R. A., and Deretic, D. (1997). Mycobacterial phagosome maturation, rab proteins, and intracellular trafficking. Electrophoresis 18, 2542-2547. doi: 10.1002/elps.115018 1409

Deshpande, D., Srivastava, S., Musuka, S., and Gumbo, T. (2016). Thioridazine as Chemotherapy for Mycobacterium avium Complex Diseases. Antimicrob. Agents Chemother. 60, 4652-4658. doi: 10.1128/aac.02985-15

Di Santo, N., and Ehrisman, J. (2014). A functional perspective of nitazoxanide as a potential anticancer drug. Mutation Res. 768, 16-21. doi: 10.1016/j.mrfmmm. 2014.05.005 
Donohue, M. J., and Wymer, L. (2016). Increasing Prevalence Rate of Nontuberculous Mycobacteria Infections in Five States, 2008-2013. Ann. Am. Thorac. Soc. 13, 2143-2150. doi: 10.1513/AnnalsATS.201605-353OC

Early, J., Fischer, K., and Bermudez, L. E. (2011). Mycobacterium avium uses apoptotic macrophages as tools for spreading. Microb. Pathogenesis 50, 132-139. doi: 10.1016/j.micpath.2010.12.004

Etna, M. P., Sinigaglia, A., Grassi, A., Giacomini, E., Romagnoli, A., Pardini, M., et al. (2018). Mycobacterium tuberculosis-induced miR-155 subverts autophagy by targeting ATG3 in human dendritic cells. PLoS Pathogens 14:e1006790. doi: 10.1371/journal.ppat. 1006790

Evans, M. J., and Levy, L. (1972). Ultrastructural Changes in Cells of the Mouse Footpad Infected with Mycobacterium leprae. Infect. Immun. 5, 238-247.

Fabri, M., Stenger, S., Shin, D.-M., Yuk, J.-M., Liu, P. T., Realegeno, S., et al. (2011). Vitamin D Is Required for IFN- $\gamma$-Mediated Antimicrobial Activity of Human Macrophages. Sci. Trans. Med. 3, ra102-ra104. doi: 10.1126/scitranslmed. 3003045

Fazeli, G., and Wehman, A. M. (2017). Rab GTPases mature the LC3-associated midbody phagosome. Commun. Integr. Biol. 10, e1297349. doi: 10.1080/ 19420889.2017.1297349

Fischer, M. (2017). Leprosy - an overview of clinical features, diagnosis, and treatment. JDDG 15, 801-827. doi: 10.1111/ddg.13301

Flores-Valdez, M. A., Segura-Cerda, C. A., and Gaona-Bernal, J. (2018). Modulation of autophagy as a strategy for development of new vaccine candidates against tuberculosis. Mole. Immunol. 97, 16-19. doi: 10.1016/j. molimm.2018.03.006

Floto, R. A., Sarkar, S., Perlstein, E. O., Kampmann, B., Schreiber, S. L., and Rubinsztein, D. C. (2007). Small Molecule Enhancers of Rapamycin-Induced TOR Inhibition Promote Autophagy, Reduce Toxicity in Huntington's Disease Models and Enhance Killing of Mycobacteria by Macrophages. Autophagy 3, 620-622. doi: 10.4161/auto.4898

Flynn, J. L., Chan, J., Triebold, K. J., Dalton, D. K., Stewart, T. A., and Bloom, B. R. (1993). An Essential Role for Interferon- $\gamma$ in Resistance to Mycobacterium tuberculosis Infection. J. Exp. Med. 178, 2249-2254. doi: 10.1084/jem.178.6. 2249

Franco-Paredes, C., Marcos, L. A., Henao-Martínez, A. F., Rodríguez-Morales, A. J., Villamil-Gómez, W. E., Gotuzzo, E., et al. (2018). Cutaneous Mycobacterial Infections. Clin. Microb. Rev. 32, e69-e18. doi: 10.1128/CMR. 00069-18s

Fujita, N., Itoh, T., Omori, H., Fukuda, M., Noda, T., and Yoshimori, T. (2008). The Atg16L Complex Specifies the Site of LC3 Lipidation for Membrane Biogenesis in Autophagy. Mole. Biol. Cell 19, 2092-2100. doi: 10.1091/mbc.e07-12-1257

Gama, J. B., Ohlmeier, S., Martins, T. G., Fraga, A. G., Sampaio-Marques, B. M., Carvalho, M. A., et al. (2014). Proteomic Analysis of the Action of the Mycobacterium ulcerans Toxin Mycolactone: Targeting Host Cells Cytoskeleton and Collagen. PLoS Neglec. Trop. Dis. 8:e3066. doi: 10.1371/journal.pntd. 0003066

Gao, L.-Y., and Kwaik, Y. A. (2000). The modulation of host cell apoptosis by intracellular bacterial pathogens. Trends Microbiol. 8, 306-313. doi: 10.1016/ S0966-842X(00)01784-4

Genestet, C., Bernard-Barret, F., Hodille, E., Ginevra, C., Ader, F., Goutelle, S., et al. (2018). Antituberculous drugs modulate bacterial phagolysosome avoidance and autophagy in Mycobacterium tuberculosisinfected macrophages. Tuberculosis 111, 67-70. doi: 10.1016/j.tube.2018. 05.014

Gengenbacher, M., Nieuwenhuizen, N., Vogelzang, A., Liu, H., Kaiser, P., Schuerer, S., et al. (2016). Deletion of nuoG from the Vaccine Candidate Mycobacterium bovis BCG $\triangle$ ureC:: hly Improves Protection against Tuberculosis. mBio 7, e679-e616. doi: 10.1128/mBio.00679-16

Ghadimi, D., de Vrese, M., Heller, K. J., and Schrezenmeir, J. (2010). Lactic acid bacteria enhance autophagic ability of mononuclear phagocytes by increasing Th1 autophagy-promoting cytokine (IFN- $\gamma$ ) and nitric oxide (NO) levels and reducing Th2 autophagy-restraining cytokines (IL-4 and IL-13) in response to Mycobacterium tuberculosis antigen. Int. Immunopharmacol. 10, 694-706. doi: 10.1016/j.intimp.2010.03.014

Gopalaswamy, R., Shanmugam, S., Mondal, R., and Subbian, S. (2020). Of tuberculosis and non-tuberculous mycobacterial infections - a comparative analysis of epidemiology, diagnosis and treatment. J.Biomed. Sci. 27, 74-74. doi: 10.1186/s12929-020-00667-6
Greendyke, R., and Byrd, T. F. (2008). Differential Antibiotic Susceptibility of Mycobacterium abscessus Variants in Biofilms and Macrophages Compared to That of Planktonic Bacteria. Antimicrob. Agents Chemother. 52, 2019-2026. doi: 10.1128/AAC.00986-07

Greenstein, R. J., Su, L., Juste, R. A., and Brown, S. T. (2008). On the Action of Cyclosporine A, Rapamycin and Tacrolimus on M. avium Including Subspecies paratuberculosis. PLoS One 3:2496. doi: 10.1371/journal.pone.0002496

Griffith, D. E. (2018). Treatment of Mycobacterium avium Complex (MAC). Semin. Respir. Crit. Care Med. 39, 351-361. doi: 10.1055/s-0038- 1660472

Griffith, D. E. (2019). "A comprehensive Approach to Diagnosis and Management," in Nontuberculosis Mycobacterial Disease, ed. D. E. Griffith (Berlin: Springer).

Griffith, D. E., Aksamit, T., Brown-Elliott, B. A., Catanzaro, A., Daley, C., Gordin, F., et al. (2007). An Official ATS/IDSA Statement: Diagnosis, Treatment, and Prevention of Nontuberculous Mycobacterial Diseases. Am. J. Respir. Crit. Care Med. 175, 367-416. doi: 10.1164.rccm.200604-571ST

Gupta, A., Ahmad, F. J., Ahmad, F., Gupta, U. D., Natarajan, M., Katoch, V., et al. (2012). Efficacy of Mycobacterium indicus pranii Immunotherapy as an Adjunct to Chemotherapy for Tuberculosis and Underlying Immune Responses in the Lung. PLoS One 7:e39215. doi: 10.1371/journal.pone.0039215

Gupta, A., Pant, G., Mitra, K., Madan, J., Chourasia, M. K., and Misra, A. (2014). Inhalable Particles Containing Rapamycin for Induction of Autophagy in Macrophages Infected with Mycobacterium tuberculosis. Mole. Pharm. 11, 1201-1207. doi: $10.1021 / \mathrm{mp} 4006563$

Gupta, A., Sharma, D., Meena, J., Pandya, S., Sachan, M., Kumar, S., et al. (2016). Preparation and Preclinical Evaluation of Inhalable Particles Containing Rapamycin and Anti-Tuberculosis Agents for Induction of Autophagy. Pharm. Res. 33, 1899-1912. doi: 10.1007/s11095-016-1926-0

Gutierrez, M. G., Master, S. S., Singh, S. B., Taylor, G. A., Colombo, M. I., and Deretic, V. (2004). Autophagy Is a Defense Mechanism Inhibiting BCG and Mycobacterium tuberculosis Survival in Infected Macrophages. Cell 119, 753-766. doi: 10.1016/j.cell.2004.11.038

Guzmán-Beltrán, S., Rubio-Badillo, M. Á, Juárez, E., Hernández-Sánchez, F., and Torres, M. (2016). Nordihydroguaiaretic acid (NDGA) and $\alpha$-mangostin inhibit the growth of Mycobacterium tuberculosis by inducing autophagy. Int. Immunopharm. 31, 149-157. doi: 10.1016/j.intimp.2015.12.027

Harris, J., De Haro, S. A., Master, S. S., Keane, J., Roberts, E. A., Delgado, M., et al. (2007). T Helper 2 Cytokines Inhibit Autophagic Control of Intracellular Mycobacterium tuberculosis. Immunity 27, 505-517. doi: 10.1016/j.immuni. 2007.07.022

Hinchey, J., Lee, S., Jeon, B. Y., Basaraba, R. J., Venkataswamy, M. M., Chen, B., et al. (2007). Enhanced priming of adaptive immunity by a proapoptotic mutant of Mycobacterium tuberculosis. J. Clin. Invest. 117, 2279-2288. doi: $10.1172 / \mathrm{JCI} 31947$

Hu, D., Wu, J., Zhang, R., Chen, L., Chen, Z., Wang, X., et al. (2014). Autophagytargeted vaccine of LC3-LpqH DNA and its protective immunity in a murine model of tuberculosis. Vaccine 32, 2308-2314. doi: 10.1016/j.vaccine.2014.02. 069

Huang, D., and Bao, L. (2016). Mycobacterium tuberculosis EspB protein suppresses interferon- $\gamma$-induced autophagy in murine macrophages. J. Microbiol. Immunol. Infect. 49, 859-865. doi: 10.1016/j.jmii.2014.11.008

Iacobino, A., Giannoni, F., Pardini, M., Piccaro, G., and Fattorini, L. (2019). The Combination Rifampin-Nitazoxanide, but Not Rifampin-IsoniazidPyrazinamide-Ethambutol, Kills Dormant Mycobacterium tuberculosis in Hypoxia at Neutral pH. Antimicrob. Agents Chemother. 63, e273-e219. doi: 10.1128/aac.00273-19

Islam, M. S., Richards, J. P., and Ojha, A. K. (2012). Targeting drug tolerance in mycobacteria: a perspective from mycobacterial biofilms. Exp. Rev. Anti-infect. Ther. 10, 1055-1066. doi: 10.1586/eri.12.88

Itakura, E., and Mizushima, N. (2010). Characterization of autophagosome formation site by a hierarchical analysis of mammalian Atg proteins. Autophagy 6, 764-776. doi: 10.4161/auto.6.6.12709

Jagannath, C., Lindsey, D. R., Dhandayuthapani, S., Xu, Y., Hunter, R. L., and Eissa, N. T. (2009). Autophagy enhances the efficacy of BCG vaccine by increasing peptide presentation in mouse dendritic cells. Nat. Med. 15, 267-276. doi: 10.1038/nm.1928

Jarlier, V., and Nikaido, H. (1990). Permeability barrier to hydrophilic solutes in Mycobacterium chelonei. J. Bacteriol. 172, 1418-1423. doi: 10.1128/jb.172.3. 1418- 1423.1990 
Jiao, Y., and Sun, J. (2019). Bacterial Manipulation of Autophagic Responses in Infection and Inflammation. Front. Immunol. 10:2821-2821. doi: 10.3389/ fimmu.2019.02821

Jo, E.-K. (2010). Innate immunity to mycobacteria: vitamin D and autophagy. Cell. Microbiol. 12, 1026-1035. doi: 10.1111/j.1462-5822.2010.01491.x

Johnson, M. M., and Odell, J. A. (2014). Nontuberculous mycobacterial pulmonary infections. J. Thorac. Dis. 6, 210-220. doi: 10.3978/j.issn.2072-1439.2013.12.24

Juárez, E., Carranza, C., Sánchez, G., González, M., Chávez, J., Sarabia, C., et al. (2016). Loperamide Restricts Intracellular Growth of Mycobacterium tuberculosis in Lung Macrophages. Am. J. Respir. Cell Mole. Biol. 55, 837-847. doi: 10.1165/rcmb.2015-0383OC

Kaushik, A., Ammerman, N. C., Martins, O., Parrish, N. M., and Nuermberger, E. L. (2019). In Vitro Activity of New Tetracycline Analogs Omadacycline and Eravacycline against Drug-Resistant Clinical Isolates of Mycobacterium abscessus. Antimicrob. Agents Chemother. 63, e470-e419. doi: 10.1128/aac. 00470-19

Keane, J., Remold, H. G., and Kornfeld, H. (2000). Virulent Mycobacterium tuberculosis Strains Evade Apoptosis of Infected Alveolar Macrophages. J. Immunol. 164, 2016-2020. doi: 10.4049/jimmunol.164.4.2016

Khan, A., Bakhru, P., Saikolappan, S., Das, K., Soudani, E., Singh, C. R., et al. (2019). An autophagy-inducing and TLR-2 activating BCG vaccine induces a robust protection against tuberculosis in mice. NPJ Vaccines 4:34. doi: 10.1038/s41541019-0122-8

Kim, J. K., Kim, T. S., Basu, J., and Jo, E.-K. (2017a). MicroRNA in innate immunity and autophagy during mycobacterial infection. Cell. Microbiol. 19:e12687. doi: $10.1111 / \mathrm{cmi} .12687$

Kim, J. K., Lee, H.-M., Park, K.-S., Shin, D.-M., Kim, T. S., Kim, Y. S., et al. (2017b). MIR144* inhibits antimicrobial responses against Mycobacterium tuberculosis in human monocytes and macrophages by targeting the autophagy protein DRAM2. Autophagy 13, 423-441. doi: 10.1080/15548627.2016.1241922

Kim, J. K., Yuk, J.-M., Kim, S. Y., Kim, T. S., Jin, H. S., Yang, C.-S., et al. (2015). MicroRNA-125a Inhibits Autophagy Activation and Antimicrobial Responses during Mycobacterial Infection. J. Immunol. 194, 5355-5365. doi: 10.4049/ jimmunol.1402557

Kim, J.-J., Lee, H.-M., Shin, D.-M., Kim, W., Yuk, J.-M., Jin, H. S., et al. (2012). Host Cell Autophagy Activated by Antibiotics Is Required for Their Effective Antimycobacterial Drug Action. Cell Host Microbe 11, 457-468. doi: 10.1016/j. chom.2012.03.008

Kim, S.-W., Subhadra, B., Whang, J., Back, Y. W., Bae, H. S., Kim, H.-J., et al. (2017c). Clinical Mycobacterium abscessus strain inhibits autophagy flux and promotes its growth in murine macrophages. Pathogens Dis. 75:107. doi: 10. 1093/femspd/ftx107

Kim, Y. S., Silwal, P., Kim, S. Y., Yoshimori, T., and Jo, E.-K. (2019). Autophagyactivating strategies to promote innate defense against mycobacteria. Exp. Mole. Med. 51, 1-10. doi: 10.1038/s12276-019-0290-7

Kimmey, J. M., Huynh, J. P., Weiss, L. A., Park, S., Kambal, A., Debnath, J., et al. (2015). Unique role for ATG5 in PMN-mediated immunopathology during M. tuberculosis infection. Nature 528, 565-569. doi: 10.1038/nature16451

Knodler, L. A., and Celli, J. (2011). Eating the strangers within: host control of intracellular bacteria via xenophagy. Cell. Microb. 13, 1319-1327. doi: 10.1111/ j.1462-5822.2011.01632.x

Kontturi, A., Soini, H., Ollgren, J., and Salo, E. (2018). Increase in Childhood Nontuberculous Mycobacterial Infections After Bacille Calmette-Guérin Coverage Drop: A Nationwide, Population-Based Retrospective Study, Finland, 1995-2016. Clin. Infect. Dis. 67, 1256-1261. doi: 10.1093/cid/ ciy 241

Köster, S., Upadhyay, S., Chandra, P., Papavinasasundaram, K., Yang, G., Hassan, A., et al. (2017). Mycobacterium tuberculosis is protected from NADPH oxidase and LC3-associated phagocytosis by the LCP protein CpsA. Proc. Natl. Acad. Sci. 114, E8711-E8720. doi: 10.1073/pnas.1707792114

Kumar, R., Sahu, S. K., Kumar, M., Jana, K., Gupta, P., Gupta, U. D., et al. (2016). MicroRNA 17-5p regulates autophagy in Mycobacterium tuberculosis-infected macrophages by targeting Mcl-1 and STAT3. Cell. Microb. 18, 679-691. doi: $10.1111 / \mathrm{cmi} .12540$

Lachmandas, E., Eckold, C., Böhme, J., Koeken, V. A. C. M., Marzuki, M. B., Blok, B., et al. (2019). Metformin Alters Human Host Responses to Mycobacterium tuberculosis in Healthy Subjects. J. Infect. Dis. 220, 139-150. doi: 10.1093/infdis/ jiz064
Lam, K. K. Y., Zheng, X., Forestieri, R., Balgi, A. D., Nodwell, M., Vollett, S., et al. (2012). Nitazoxanide Stimulates Autophagy and Inhibits mTORC1 Signaling and Intracellular Proliferation of Mycobacterium tuberculosis. PLoS Pathogens 8:e1002691. doi: 10.1371/journal.ppat.1002691

Lawlor, C., O'Connor, G., O'Leary, S., Gallagher, P. J., Cryan, S.-A., Keane, J., et al. (2016). Treatment of Mycobacterium tuberculosis-Infected Macrophages with Poly(Lactic-Co-Glycolic Acid) Microparticles Drives NFkB and Autophagy Dependent Bacillary Killing. PLoS One 11:e0149167. doi: 10.1371/journal.pone. 0149167

Lee, E. G., Boone, D. L., Chai, S., Libby, S. L., Chien, M., Lodolce, J. P., et al. (2000). Failure to Regulate TNF-Induced NF-кB and Cell Death Responses in A20-Deficient Mice. Science 289, 2350-2354. doi: 10.1126/science.289.5488. 2350

Lee, G. J., Lee, H.-M., Kim, T. S., Kim, J. K., Sohn, K. M., and Jo, E.-K. (2016). Mycobacterium fortuitum induces A20 expression that impairs macrophage inflammatory responses. Pathog. Dis. 74:015. doi: 10.1093/femspd/ftw015

Lee, J., Repasy, T., Papavinasasundaram, K., Sassetti, C., and Kornfeld, H. (2011). Mycobacterium tuberculosis Induces an Atypical Cell Death Mode to Escape from Infected Macrophages. PLoS One 6:18367. doi: 10.1371/journal.pone. 0018367

Lee, Y.-J., Han, S. K., Park, J. H., Lee, J. K., Kim, D. K., Chung, H. S., et al. (2018). The effect of metformin on culture conversion in tuberculosis patients with diabetes mellitus. Korean J. Int. Med. 33, 933-940. doi: 10.3904/kjim.2017.249

Lella, R. K., and Sharma, C. (2007). Eis (Enhanced Intracellular Survival) Protein of Mycobacterium tuberculosis Disturbs the Cross Regulation of T-cells. J. Biol. Chem. 282, 18671-18675. doi: 10.1074/jbc.C600280200

Lerena, M. C., and Colombo, M. I. (2011). Mycobacterium marinum induces a marked LC3 recruitment to its containing phagosome that depends on a functional ESX-1 secretion system. Cell. Microb. 13, 814-835. doi: 10.1111/j. 1462-5822.2011.01581.x

Levine, B., Mizushima, N., and Virgin, H. W. (2011). Autophagy in immunity and inflammation. Nature 469, 323-335. doi: 10.1038/nature09782

Li, F., Gao, B., Xu, W., Chen, L., and Xiong, S. (2016). The Defect in Autophagy Induction by Clinical Isolates of Mycobacterium Tuberculosis Is Correlated with Poor Tuberculosis Outcomes. PLoS One 11:e0147810. doi: 10.1371/ journal.pone. 0147810

Li, M., Cui, J., Niu, W., Huang, J., Feng, T., Sun, B., et al. (2019). Long non-coding PCED1B-AS1 regulates macrophage apoptosis and autophagy by sponging miR-155 in active tuberculosis. Biochem. Biophy. Res. Commun. 509, 803-809. doi: 10.1016/j.bbrc.2019.01.005

Li, X., Lu, J., Xu, Y., Wang, J., Qiu, X., Fan, L., et al. (2020). Discovery of nitazoxanide-based derivatives as autophagy activators for the treatment of Alzheimer's disease. Acta Pharmaceutica Sinica B 10, 646-666. doi: 10.1016/j. apsb.2019.07.006

Lin, C., Tsai, S.-C., Tseng, M. T., Peng, S.-F., Kuo, S.-C., Lin, M.-W., et al. (2013). AKT serine/threonine protein kinase modulates baicalin-triggered autophagy in human bladder cancer T24 cells. Int. J. Oncol. 42, 993-1000. doi: 10.3892/ijo. 2013.1791

Liu, F., Chen, J., Wang, P., Li, H., Zhou, Y., Liu, H., et al. (2018). MicroRNA-27a controls the intracellular survival of Mycobacterium tuberculosis by regulating calcium-associated autophagy. Nat. Commun. 9:4295. doi: 10.1038/s41467-01806836-4

Liu, P. T., Stenger, S., Tang, D. H., and Modlin, R. L. (2007). Cutting Edge: Vitamin D-Mediated Human Antimicrobial Activity against Mycobacterium tuberculosis Is Dependent on the Induction of Cathelicidin. J. Immunol. 179, 2060-2063. doi: 10.4049/jimmunol.179.4.2060

Manry, J., Vincent, Q. B., Johnson, C., Chrabieh, M., Lorenzo, L., Theodorou, I., et al. (2020). Genome-wide association study of Buruli ulcer in rural Benin highlights role of two LncRNAs and the autophagy pathway. Sci. Rep. 3:177. doi: 10.1038/s42003-020-0920-6

Marini, E., Di Giulio, M., Ginestra, G., Magi, G., Di Lodovico, S., Marino, A., et al. (2019). Efficacy of carvacrol against resistant rapidly growing mycobacteria in the planktonic and biofilm growth mode. PLoS One 14:e0219038. doi: 10.1371/ journal.pone. 0219038

Martineau, A. R., Wilkinson, K. A., Newton, S. M., Floto, R. A., Norman A. W., Skolimowska, K., et al. (2007). IFN- $\gamma$ - and TNF-Independent Vitamin D-Inducible Human Suppression of Mycobacteria: The Role of Cathelicidin LL-37. J. Immunol. 178, 7190-7198. doi: 10.4049/jimmunol.178.11.7190 
Marupuru, S., Senapati, P., Pathadka, S., Miraj, S. S., Unnikrishnan, M. K., and Manu, M. K. (2017). Protective effect of metformin against tuberculosis infections in diabetic patients: an observational study of south Indian tertiary healthcare facility. Brazilian J. Infect. Dis. 21, 312-316.

Matsunaga, K., Saitoh, T., Tabata, K., Omori, H., Satoh, T., Kurotori, N., et al. (2009). Two Beclin 1-binding proteins, Atg14L and Rubicon, reciprocally regulate autophagy at different stages. Nat. Cell Biol. 11, 385-396. doi: 10.1038/ ncb1846

Maymone, M. B. C., Venkatesh, S., Laughter, M., Abdat, R., Hugh, J., Dacso, M. M., et al. (2020). Leprosy: Treatment and management of complications. J. Am. Acad. Dermatol. 83, 17-30. doi: 10.1016/j.jaad.2019.10.138

Meerak, J., Wanichwecharungruang, S. P., and Palaga, T. (2013). Enhancement of immune response to a DNA vaccine against Mycobacterium tuberculosis Ag85B by incorporation of an autophagy inducing system. Vaccine 31, 784-790. doi: 10.1016/j.vaccine.2012.11.075

Mishra, M., Adhyapak, P., Dadhich, R., and Kapoor, S. (2019). Dynamic Remodeling of the Host Cell Membrane by Virulent Mycobacterial Sulfoglycolipid-1. Sci. Rep. 9:12844.

Mizushima, N. (2010). The role of the Atg1/ULK1 complex in autophagy regulation. Curr. Opin. Cell Biol. 22, 132-139. doi: 10.1016/j.ceb.2009.12.004

Moore, M., and Frerichs, J. B. (1953). An Unusual Acid-Fast Infection of the Knee with Subcutaneous, Abscess-Like Lesions of the Gluteal Region: Report of a Case with a Study of the Organism, Mycobacterium abscessus, n. sp. J. Investig. Dermatol. 20, 133-169. doi: 10.1038/jid.1953.18

Münz, C. (2016). Autophagy Beyond Intracellular MHC Class II Antigen Presentation. Trends Immunol. 37, 755-763. doi: 10.1016/j.it.2016.08.017

N'Goma, J. C. B., Le Moigne, V., Soismier, N., Laencina, L., Le Chevalier, F., Roux, A.-L., et al. (2015). Mycobacterium abscessus phospholipase C expression is induced during coculture within amoebae and enhances $M$. abscessus virulence in mice. Infect. Immun. 83, 780-791. doi: 10.1128/IAI.02032-14

Naicker, N., Sigal, A., and Naidoo, K. (2020). Metformin as Host-Directed Therapy for TB Treatment: Scoping Review. Front. Microb. 11:435-435. doi: 10.3389/ fmicb.2020.00435

Nath, I. (2016). IMMUNOPATHOGENESIS OF LEPROSY: A MODEL FOR T CELL ANERGY. EMJ Dermatol. 4, 95-101.

Nessar, R., Cambau, E., Reyrat, J. M., Murray, A., and Gicquel, B. (2012). Mycobacterium abscessus: a new antibiotic nightmare. J. Antimicrob. Chemother. 67, 810-818. doi: 10.1093/jac/dkr578

Nieuwenhuizen, N. E., Kulkarni, P. S., Shaligram, U., Cotton, M. F., Rentshce, C. A., Eisele, B., et al. (2017). The Recombinant Bacille Calmette_Guerin Vaccine BPM1002: Ready for Clinical Efficacy Testing. Front. Immunol. 8:1147. doi: 10.3389/fimmu.2017.01147

Nowotarska, S. W., Nowotarski, K., Grant, I. R., Elliott, C. T., Friedman, M., and Situ, C. (2017). Mechanisms of Antimicrobial Action of Cinnamon and Oregano Oils, Cinnamaldehyde, Carvacrol, 2,5-Dihydroxybenzaldehyde, and 2-Hydroxy-5-Methoxybenzaldehyde against Mycobacterium avium subsp. paratuberculosis (Map). Foods 6:72.

Ogawa, M., Yoshimori, T., Suzuki, T., Sagara, H., Mizushima, N., and Sasakawa, C. (2005). Escape of Intracellular Shigella from Autophagy. Science 307, 727-731. doi: 10.1126/science.1106036

Oliveira, F. M., Marinho, F. V., Oliveira, S. C., Resende, D. P., Junqueira-Kipnis, A. P., and Kipnis, A. (2020). Mycobacterium abscessus subsp. massiliense expressing bacterioferritin have improved resistance to stressful conditions. J. Appl. Microb. 128, 1802-1813. doi: 10.1111/jam.14585

Padmapriyadarsini, C., Bhavani, P. K., Natrajan, M., Ponnuraja, C., Kumar, H., Gomathy, S. N., et al. (2019). Evaluation of metformin in combination with rifampicin containing antituberculosis therapy in patients with new, smearpositive pulmonary tuberculosis (METRIF): study protocol for a randomised clinical trial. BMJ Open 9:e024363. doi: 10.1136/bmjopen-2018-024363

Pahari, S., Negi, S., Aqdas, M., Arnett, E., Schlesinger, L. S., and Agrewala, J. N. (2020). Induction of autophagy through CLEC4E in combination with TLR4: an innovative strategy to restrict the survival of Mycobacterium tuberculosis. Autophagy 16, 1021-1043. doi: 10.1080/15548627.2019.1658436

Parihar, S. P., Guler, R., Khutlang, R., Lang, D. M., Hurdayal, R., Mhlanga, M. M., et al. (2013). Statin Therapy Reduces the Mycobacterium tuberculosis Burden in Human Macrophages and in Mice by Enhancing Autophagy and Phagosome Maturation. J. Infect. Dis. 209, 754-763. doi: 10.1093/infdis/jit550
Parzych, K. R., and Klionsky, D. J. (2013). An Overview of Autophagy: Morphology, Mechanism, and Regulation. Antioxidants Redox Signal. 20, 460473. doi: 10.1089/ars.2013.5371

Pohl, K., Grimm, X. A., Caceres, S. M., Poch, K. R., Rysavy, N., Saavedra, M., et al. (2020). Mycobacterium abscessus clearance by neutrophils is independent of autophagy. Infect. Immun. 88, e24-e20. doi: 10.1128/IAI.00024-20

Polson, H. E. J., de Lartigue, J., Rigden, D. J., Reedijk, M., Urbé, S., Clague, M. J., et al. (2010). Mammalian Atg18 (WIPI2) localizes to omegasome-anchored phagophores and positively regulates LC3 lipidation. Autophagy 6, 506-522. doi: 10.4161/auto.6.4.11863

Popa, C., Li, L., Gil, S., Tatjer, L., Hashii, K., Tabuchi, M., et al. (2016). The effector AWR5 from the plant pathogen Ralstonia solanacearum is an inhibitor of the TOR signalling pathway. Sci. Rep. 6:27058. doi: 10.1038/srep27058

Potoènjak, I., Gobin, I., and Domitroviæ, R. (2018). Carvacrol induces cytotoxicity in human cervical cancer cells but causes cisplatin resistance: Involvement of MEK-ERK activation. Phytother. Res. 32, 1090-1097. doi: 10.1002/ptr.6048

Prevots, D. R., Shaw, P. A., Strickland, D., Jackson, L. A., Raebel, M. A., Blosky, M. A., et al. (2010). Nontuberculous Mycobacterial Lung Disease Prevalence at Four Integrated Health Care Delivery Systems. Am. J. Respir. Crit. Care Med. 182, 970-976. doi: 10.1164/rccm.201002-0310OC

Ratnatunga, C. N., Lutzky, V. P., Kupz, A., Doolan, D. L., Reid, D. W., Field, M., et al. (2020). The Rise of Non-Tuberculosis Mycobacterial Lung Disease. Front. Immunol. 11:303. doi: 10.3389/fimmu.2020.00303

Ravindran, R., Khan, N., Nakaya, H. I., Li, S., Loebbermann, J., Maddur, M. S., et al. (2014). Vaccine Activation of the Nutrient Sensor GCN2 in Dendritic Cells Enhances Antigen Presentation. Science 343, 313-317. doi: 10.1126/science. 1246829

Rekha, R. S., Rao Muvva, S. S. V. J., Wan, M., Raqib, R., Bergman, P., Brighenti, S., et al. (2015). Phenylbutyrate induces LL-37-dependent autophagy and intracellular killing of Mycobacterium tuberculosis in human macrophages. Autophagy 11, 1688-1699. doi: 10.1080/15548627.2015.1075110

Renna, M., Schaffner, C., Brown, K., Shang, S., Henao Tamayo, M., Hegyi, K., et al. (2011). Azithromycin blocks autophagy and may predispose cystic fibrosis patients to mycobacterial infection. J. Clin. Investig. 1219, 2554-3563. doi: 10. 1172/JCI46095

Restrepo, B. I. (2016). Metformin: Candidate host-directed therapy for tuberculosis in diabetes and non-diabetes patients. Tuberculosis 101, S69-S72. doi: 10.1016/ j.tube.2016.09.008

Rink, J., Ghigo, E., Kalaidzidis, Y., and Zerial, M. (2005). Rab Conversion as a Mechanism of Progression from Early to Late Endosomes. Cell 122, 735-749. doi: 10.1016/j.cell.2005.06.043

Rodrigues, L., Wagner, D., Viveiros, M., Sampaio, D., Couto, I., Vavra, M., et al. (2008). Thioridazine and chlorpromazine inhibition of ethidium bromide efflux in Mycobacterium avium and Mycobacterium smegmatis. J. Antimicrob. Chemother. 61, 1076-1082. doi: 10.1093/jac/dkn070

Röltgen, K., and Pluschke, G. (2015). Epidemiology and disease burden of Buruli ulcer: a review. Res. Rep. Trop. Med. 6, 59-73. doi: 10.2147/RRTM.S62026

Romagnoli, A., Etna, M. P., Giacomini, E., Pardini, M., Remoli, M. E., Corazzari, M., et al. (2012). ESX-1 dependent impairment of autophagic flux by Mycobacterium tuberculosis in human dendritic cells. Autophagy 8, 1357-1370. doi: 10.4161/auto.20881

Rossignol, J.-F. (1999). Method For Treatment Of Opportunistic Infections With Pharmaceutical Compositions Of Tizoxanide And Nitazoxanide. U S Patent Appl. 5:590.

Roux, A.-L., Viljoen, A., Bah, A., Simeone, R., Bernut, A., Laencina, L., et al. (2016). The distinct fate of smooth and rough Mycobacterium abscessus variants inside macrophages. Open Biol. 6:160185. doi: 10.1098/rsob.160185

Rudra, J. S., Khan, A., Clover, T. M., Endsley, J. J., Zloza, A., Wang, J., et al. (2017). Supramolecular Peptide Nanofibers Engage Mechanisms of Autophagy in Antigen-Presenting Cells. ACS Omega 2, 9136-9143. doi: 10.1021/acsomega. 7 b00525

Russell, D. G., Mwandumba, H. C., and Rhoades, E. E. (2002). Mycobacterium and the coat of many lipids. J. Cell Biol. 158:200205034. doi: 10.1083/jcb.200205034

SAGE Working Group of BCG Vaccines, and WHO Secretariat (2017). Report on BCG vaccine use for protection against mycobacterial infections including tuberculosis, leprosy, and other nontuberculous mycobacteria (NTM) infections. Thousand Oaks,CA: SAGE. 
Saini, N. K., Baena, A., Ng, T. W., Venkataswamy, M. M., Kennedy, S. C., Kunnath-Velayudhan, S., et al. (2016). Suppression of autophagy and antigen presentation by Mycobacterium tuberculosis PE_PGRS47. Nat. Microb. 1:16133. doi: 10.1038/nmicrobiol.2016.133

Sakowski, E. T., Koster, S., Portal Celhay, C., Park, H. S., Shrestha, E., Hetzenecker, S. E., et al. (2015). Ubiquilin 1 Promotes IFN- $\gamma$-Induced Xenophagy of Mycobacterium tuberculosis. PLoS Pathogens 11:e1005076. doi: 10.1371/ journal.ppat.1005076

Samuel, L. P., Song, C.-H., Wei, J., Roberts, E. A., Dahl, J. L., and Barry, C. E. (2007). Expression, production and release of the Eis protein by Mycobacterium tuberculosis during infection of macrophages and its effect on cytokine secretion. Microbiology 153, 529-540. doi: 10.1099/mic.0.2006/002642-0

Sanguinetti, M., Ardito, F., Fiscarelli, E., La Sorda, M., D’Argenio, P., Ricciotti, G., et al. (2001). Fatal Pulmonary Infection Due to Multidrug-Resistant Mycobacterium abscessus in a Patient with Cystic Fibrosis. J. Clin. Microb. 39, 816-819. doi: 10.1128/JCM.39.2.816-819.2001

Saqib, M., Khatri, R., Singh, B., Gupta, A., Kumar, A., and Bhaskar, S. (2016). Mycobacterium indicus pranii as a booster vaccine enhances BCG induced immunity and confers higher protection in animal models of tuberculosis. Tuberculosis 101, 164-173. doi: 10.1016/j.tube.2016.10.002

Sarkar, S., Davies, J. E., Huang, Z., Tunnacliffe, A., and Rubinsztein, D. C. (2007). Trehalose, a Novel mTOR-independent Autophagy Enhancer, Accelerates the Clearance of Mutant Huntingtin and $\alpha$-Synuclein. J. Biol. Chem. 282, 56415652. doi: $10.1074 /$ jbc.M609532200

Sarkar, S., Korolchuk, V. I., Renna, M., Imarisio, S., Fleming, A., Williams, A., et al. (2011). Complex Inhibitory Effects of Nitric Oxide on Autophagy. Mole. Cell 43, 19-32. doi: 10.1016/j.molcel.2011.04.029

Schiebler, M., Brown, K., Hegyi, K., Newton, S. M., Renna, M., Hepburn, L., et al. (2015). Functional drug screening reveals anticonvulsants as enhancers of mTOR-independent autophagic killing of Mycobacterium tuberculosis through inositol depletion. EMBO Mole. Med. 7, 127-139. doi: 10.15252/emmm. 201404137

Scollard, D. M. (2020). Leprosy treatment: Can we replace opinions with research? PLoS Neglec. Trop. Dis. 14:e0008636. doi: 10.1371/journal.pntd.0008636

Seervi, M., Rani, A., Sharma, A. K., and Santhosh Kumar, T. R. (2018). ROS mediated ER stress induces Bax-Bak dependent and independent apoptosis in response to Thioridazine. Biomed. Pharmacother. 106, 200-209. doi: 10.1016/j. biopha.2018.06.123

Seto, S., Tsujimura, K., and Koide, Y. (2012). Coronin-1a inhibits autophagosome formation around Mycobacterium tuberculosis-containing phagosomes and assists mycobacterial survival in macrophages. Cell. Microb. 14, 710-727. doi: $10.1111 / \mathrm{j} .1462-5822.2012 .01754 . \mathrm{x}$

Sharma, S. K., Katoch, K., Sarin, R., Balambal, R., Kumar Jain, N., Patel, N., et al. (2017). Efficacy and Safety of Mycobacterium indicus pranii as an adjunct therapy in Category II pulmonary tuberculosis in a randomized trial. Sci. Rep. 7:3354. doi: 10.1038/s41598-017-03514-1

Sharma, V., Makhdoomi, M., Singh, L., Kumar, P., Khan, N., Singh, S., et al. (2020). Trehalose limits opportunistic mycobacterial survival during HIV coinfection by reversing HIV-mediated autophagy block. Autophagy 2020, 1-20. doi: 10.1080/15548627.2020.1725374

Shin, D.-M., Jeon, B.-Y., Lee, H.-M., Jin, H. S., Yuk, J.-M., Song, C.-H., et al. (2010). Mycobacterium tuberculosis Eis Regulates Autophagy, Inflammation, and Cell Death through Redox-dependent Signaling. PLoS Pathogens 6:e1001230. doi: 10.1371/journal.ppat.1001230

Shin, J. H., Park, S. J., Jo, Y. K., Kim, E. S., Kang, H., Park, J. H., et al. (2012). Suppression of autophagy exacerbates Mefloquine-mediated cell death. Neurosci. Lett. 515, 162-167. doi: 10.1016/j.neulet.2012.03.040

Shoen, C., Benaroch, D., Sklaney, M., and Cynamon, M. (2019). In Vitro Activities of Omadacycline against Rapidly Growing Mycobacteria. Antimicrob. Agents Chemother. 63, e2522-e2518. doi: 10.1128/aac.02522-18

Shui, W., Petzold, C. J., Redding, A., Liu, J., Pitcher, A., Sheu, L., et al. (2011). Organelle Membrane Proteomics Reveals Differential Influence of Mycobacterial Lipoglycans on Macrophage Phagosome Maturation and Autophagosome Accumulation. J. Prot. Res. 10, 339-348. doi: 10.1021/ pr100688h

Sieling, P. A., and Modlin, R. L. (1994). Cytokine Patterns at the Site of Mycobacterial Infection. Immunobiology 191, 378-387. doi: 10.1016/S01712985(11)80443-2
Silva, B. J. D. A., Barbosa, M. G. D. M., Andrade, P. R., Ferreira, H., Nery, J. A. D. C., Côrte-Real, S., et al. (2017a). Autophagy Is an Innate Mechanism Associated with Leprosy Polarization. PLoS Pathogens 13:e1006103. doi: 10.1371/journal. ppat. 1006103

Silva, T., Moreira, A. C., Nazmi, K., Moniz, T., Vale, N., Rangel, M., et al. (2017b). Lactoferricin Peptides Increase Macrophages' Capacity To Mycobacterium avium. mSphere 2, e00301-e00317. doi: 10.1128/mSphere.00301-17

Simpson, H., Deribe, K., Tabah, E. N., Peters, A., Maman, I., Frimpong, M., et al. (2019). Mapping the global distribution of Buruli ulcer: a systematic review with evidence consensus. Lancet. Glob. Health 7, e912-e922. doi: 10.1016/S2214109X(19)30171-8

Singh, B., Saqib, M., Chakraborty, A., and Bhaskar, S. (2019). Lipoarabinomannan from Mycobacterium indicus pranii shows immunostimulatory activity and induces autophagy in macrophages. PLoS One 14:224239. doi: 10.1371/journal. pone.0224239

Singh, B., Saqib, M., Gupta, A., Kumar, P., and Bhaskar, S. (2017). Autophagy induction by Mycobacterium indicus pranii promotes Mycobacterium tuberculosis clearance from RAW 264.7 macrophages. PLoS One 12:189606. doi: 10.1371/journal.pone.0189606

Singh, C. R., Moulton, R. A., Armitige, L. Y., Bidani, A., Snuggs, M., Dhandayuthapani, S., et al. (2006). Processing and Presentation of a Mycobacterial Antigen 85B Epitope by Murine Macrophages Is Dependent on the Phagosomal Acquisition of Vacuolar Proton ATPase and In Situ Activation of Cathepsin D. J. Immunol. 177, 3250-3259. doi: 10.4049/jimmunol.177.5. 3250

Singh, K., Sun, S., and Vëzina, C. (1979). Rapamycin (Ay-22, 989), A New Antifungal Antibiotic. J. Antibiot. 32:630. doi: 10.7164/antibiotics.32.630

Singh, V. K., Berry, L., Bernut, A., Singh, S., Carrère-Kremer, S., Viljoen, A., et al. (2016). A unique PE_PGRS protein inhibiting host cell cytosolic defenses and sustaining full virulence of Mycobacterium marinum in multiple hosts. Cell. Microb. 18, 1489-1507. doi: 10.1111/cmi.12606

Singhal, A., Jie, L., Kumar, P., Hong, G. S., Leow, M. K.-S., Paleja, B., et al. (2014). Metformin as adjunct antituberculosis therapy. Sci. Trans. Med. 6, ra159-ra263. doi: 10.1126/scitranslmed.3009885

Sogi, K. M., Lien, K. A., Johnson, J. R., Krogan, N. J., and Stanley, S. A. (2017). The Tyrosine Kinase Inhibitor Gefitinib Restricts Mycobacterium tuberculosis Growth through Increased Lysosomal Biogenesis and Modulation of Cytokine Signaling. ACS Infect. Dis. 3, 564-574. doi: 10.1021/acsinfecdis.7b00046

Spalletta, S., Flati, V., Toniato, E., Di Gregorio, J., Marino, A., Pierdomenico, L., et al. (2018). Carvacrol reduces adipogenic differentiation by modulating autophagy and ChREBP expression. PLoS One 13:e0206894. doi: 10.1371/ journal.pone.0206894

Stanley, S. A., Barczak, A. K., Silvis, M. R., Luo, S. S., Sogi, K., Vokes, M., et al. (2014). Identification of Host-Targeted Small Molecules That Restrict Intracellular Mycobacterium tuberculosis Growth. PLoS Pathogens 10:e1003946. doi: 10.1371/journal.ppat.1003946

Strong, E. J., Jurcic Smith, K. L., Saini, N. K., Ng, T. W., Porcelli, S. A., and Lee, S. (2020). Identification of Autophagy-Inhibiting Factors of Mycobacterium tuberculosis by High-Throughput Loss-of-Function Screening. Infect. Immun. 88, e269-e220. doi: 10.1128/iai.00269-20

Sundaramurthy, V., Barsacchi, R., Samusik, N., Marsico, G., Gilleron, J., Kalaidzidis, I., et al. (2013). Integration of Chemical and RNAi Multiparametric Profiles Identifies Triggers of Intracellular Mycobacterial Killing. Cell Host Microb. 13, 129-142. doi: 10.1016/j.chom.2013.01.008

Svenning, S., and Johansen, T. (2013). Selective autophagy. Essays Biochem. 55, 79-92. doi: 10.1042/BSE0550079

Tao, S., and Drexler, I. (2020). Targeting Autophagy in Innate Immune Cells: Angel or Demon During Infection and Vaccination? Front. Immunol. 11:460. doi: $10.3389 /$ fimmu.2020.00460

Thurston, T. L., Ryzhakov, G., Bloor, S., von Muhlinen, N., and Randow, F. (2009). The TBK1 adaptor and autophagy receptor NDP52 restricts the proliferation of ubiquitin-coated bacteria. Nat. Immunol. 10, 1215-1221. doi: 10.1038/ni.1800

Torfs, E., Piller, T., Cos, P., and Cappoen, D. (2019). Opportunities for Overcoming Mycobacterium tuberculosis Drug Resistance: Emerging Mycobacterial Targets and Host-Directed Therapy. Int. J. Mole. Sci. 20:2868.

Tortoli, E. (2009). Clinical manifestations of nontuberculous mycobacteria infections. Clin. Microb. Infect. 15, 906-910. doi: 10.1111/j.1469-0691.2009. 03014.x 
Tseng, C.-H. (2018). Metformin Decreases Risk of Tuberculosis Infection in Type 2 Diabetes Patients. J. Clin. Med. 7:264.

Uaska Sartori, Priscila, V., Penna, G. O., Bührer-Sékula, S., Pontes Maria, A. A., Gonçalves, H. S., et al. (2020). Human Genetic Susceptibility of Leprosy Recurrence. Sci. Rep. 10:1284. doi: 10.1038/s41598-020-58079-3

Ustianowski, A., Shaffer, R., Collin, S., Wilkinson, R. J., and Davidson, R. N. (2005). Prevalence and associations of vitamin D deficiency in foreign-born persons with tuberculosis in London. J. Infect. 50, 432-437. doi: 10.1016/j.jinf.2004.07. 006

Via, L. E., Deretic, D., Ulmer, R. J., Hibler, N. S., Huber, L. A., and Deretic, V. (1997). Arrest of Mycobacterial Phagosome Maturation Is Caused by a Block in Vesicle Fusion between Stages Controlled by rab5 and rab7. J. Biol. Chem. 272, 13326-13331. doi: 10.1074/jbc.272.20.13326

Wang, J., Yang, K., Zhou, L., MinhaoWu, Wu, Y., Zhu, M., et al. (2013). MicroRNA155 Promotes Autophagy to Eliminate Intracellular Mycobacteria by Targeting Rheb. PLoS Pathogens 9:e1003697. doi: 10.1371/journal.ppat.1003697

Watson, R. O., Manzanillo, P. S., and Cox, J. S. (2012). Extracellular M. tuberculosis DNA Targets Bacteria for Autophagy by Activating the Host DNA-Sensing Pathway. Cell 150, 803-816. doi: 10.1016/j.cell.2012.06.040

Watson, Robert, O., Bell, Samantha, L., MacDuff, Donna, A., et al. (2015). The Cytosolic Sensor cGAS Detects Mycobacterium tuberculosis DNA to Induce Type I Interferons and Activate Autophagy. Cell Host Microb. 17, 811-819. doi: 10.1016/j.chom.2015.05.004

Wei, J., Dahl, J. L., Moulder, J. W., Roberts, E. A., O'Gaora, P., Young, D. B., et al. (2000). Identification of a Mycobacterium tuberculosis Gene That Enhances Mycobacterial Survival in Macrophages. J. Bacteriol. 182, 377-384. doi: 10.1128/ JB. $182.2 .377-384.2000$

Wild, P., Farhan, H., McEwan, D. G., Wagner, S., Rogov, V. V., Brady, N. R., et al. (2011). Phosphorylation of the Autophagy Receptor Optineurin Restricts Salmonella Growth. Science 333, 228-233. doi: 10.1126/science. 1205405

Williams, A., Sarkar, S., Cuddon, P., Ttofi, E. K., Saiki, S., Siddiqi, F. H., et al. (2008). Novel targets for Huntington's disease in an mTOR-independent autophagy pathway. Nat. Chem. Biol. 4, 295-305. doi: 10.1038/nchembio.79

World Health Organisation (2019). Buruli ulcer (Mycobacterium ulcerans infection) [Online]. Geneva: World Health Organisation.

World Health Organisation (2020). Global tuberculosis report 2019. Geneva: World Health Organisation.

World Health Organization (2016). Global leprosy update, 2015: time for action, accountability and inclusion. Weekly Epidemiolog. Rec. 91, 405-416.

Xu, X., Araki, K., Li, S., Han, J.-H., Ye, L., Tan, W. G., et al. (2014). Autophagy is essential for effector CD8+ T cell survival and memory formation. Nat. Immunol. 15, 1152-1161. doi: 10.1038/ni.3025

Xu, Y., Fattah, E. A., Liu, X.-D., Jagannath, C., and Eissa, N. T. (2013). Harnessing of TLR-mediated autophagy to combat mycobacteria in macrophages. Tuberculosis 93, S33-S37. doi: 10.1016/S1472-9792(13)70008-8

Xu, Y., Jagannath, C., Liu, X.-D., Sharafkhaneh, A., Kolodziejska, K. E., and Eissa, N. T. (2007). Toll-like Receptor 4 Is a Sensor for Autophagy Associated with Innate Immunity. Immunity 27, 135-144. doi: 10.1016/j.immuni.2007.05.022

Yamamura, M. (1992). Defining protective responses to pathogens: cytokine profiles in leprosy lesions. Science 255, 12-12. doi: 10.1126/science.1553522
Yang, D., Chen, J., Shi, C., Jing, Z., and Song, N. (2014). Autophagy gene polymorphism is associated with susceptibility to leprosy by affecting inflammatory cytokines. Inflammation 37, 593-598. doi: 10.1007/s10753-0139773-1

Yew, W.-W., Chan, D. P., Chang, K.-C., and Zhang, Y. (2020). How does metformin act as a host-directed agent in tuberculosis associated with diabetes mellitus? J. Thorac. Dis. 12, 1124-1126. doi: 10.21037/jtd.2020.01.30

Yotsu, R. R., Richardson, M., and Ishii, N. (2018). Drugs for treating Buruli ulcer (Mycobacterium ulcerans disease). Cochrane Database Syst. Rev. 8:CD012118. doi: 10.1002/14651858.cd012118.pub2

Yu, L., Chen, Y., and Tooze, S. A. (2018). Autophagy pathway: Cellular and molecular mechanisms. Autophagy 14, 207-215. doi: 10.1080/15548627.2017. 1378838

Yuk, J.-M., and Jo, E.-K. (2014). Host immune responses to mycobacterial antigens and their implications for the development of a vaccine to control tuberculosis. cevr 3, 155-167. doi: 10.7774/cevr.2014.3.2.155

Yuk, J.-M., Shin, D.-M., Lee, H.-M., Yang, C.-S., Jin, H. S., Kim, K.-K., et al. (2009). Vitamin D3 Induces Autophagy in Human Monocytes/Macrophages via Cathelicidin. Cell Host Microb. 6, 231-243. doi: 10.1016/j.chom.2009.08.004

Zhang, J., Chen, C., and Yang, J. (2019). Effectiveness of vitamin D supplementation on the outcome of pulmonary tuberculosis treatment in adults: a meta-analysis of randomized controlled trials. Chin. Med. J. 132, 2950-2959. doi: 10.1097/ CM9.0000000000000554

Zhang, Q., Sun, J., Wang, Y., He, W., Wang, L., Zheng, Y., et al. (2017). Antimycobacterial and Anti-inflammatory Mechanisms of Baicalin via Induced Autophagy in Macrophages Infected with Mycobacterium tuberculosis. Front. Microb. 8:2142. doi: 10.3389/fmicb.2017.02142

Zheng, Y. T., Shahnazari, S., Brech, A., Lamark, T., Johansen, T., and Brumell, J. H. (2009). The Adaptor Protein p62/SQSTM1 Targets Invading Bacteria to the Autophagy Pathway. J. Immunol. 183, 5909-5916. doi: 10.4049/jimmunol. 0900441

Zullo, A. J., and Lee, S. (2012a). Mycobacterial induction of autophagy varies by species and occurs independently of mammalian target of rapamycin inhibition. J. Biol. Chem. 287:32013. doi: 10.1074/jbc.M111.32013

Zullo, A. J., and Lee, S. (2012b). Old Antibiotics Target TB with a New Trick. Cell Host Microb. 11, 419-420. doi: 10.1016/j.chom.2012.05.002

Zullo, A. J., Jurcic Smith, K. L., and Lee, S. (2014). Mammalian target of Rapamycin inhibition and mycobacterial survival are uncoupled in murine macrophages. BMC Biochem. 15:4. doi: 10.1186/1471-2091-15-4

Conflict of Interest: The authors declare that the research was conducted in the absence of any commercial or financial relationships that could be construed as a potential conflict of interest.

Copyright (c) 2021 Strong and Lee. This is an open-access article distributed under the terms of the Creative Commons Attribution License (CC BY). The use, distribution or reproduction in other forums is permitted, provided the original author(s) and the copyright owner(s) are credited and that the original publication in this journal is cited, in accordance with accepted academic practice. No use, distribution or reproduction is permitted which does not comply with these terms. 